\title{
The Gut Microflora and its Metabolites Regulate the Molecular Crosstalk between Diabetes and Neurodegeneration
}

\author{
Susan Westfall ${ }^{1}$, Nikita Lomis ${ }^{1}$, Surya Pratap Singh ${ }^{2}$, Si Yuan Dai ${ }^{1}$ and Satya Prakash ${ }^{1 *}$
}

${ }^{1}$ Biomedical Technology and Cell Therapy Research Laboratory, Department of Biomedical Engineering, Department of Experimental Medicine, Faculty of Medicine, McGill University, 3775 University Street, Montreal, Quebec, H3A2B4, Canada

${ }^{2}$ Department of Biochemistry, Faculty of Science, Banaras Hindu University, Varanasi, 221005, Uttar Pradesh, India

\begin{abstract}
The gut microflora is a community of trillions of bacterial cells synergistically inhabiting the human gastrointestinal tract. These microbes contact everything that is consumed and release regulatory factors that affect host energy homeostasis, lipid and carbohydrate metabolism, activation of immune cells, oxidative state, epithelial cell wall integrity and even neurological signals. The gut microflora is essentially an independent organ supporting human health where imbalances in the gut community populations (dysbiosis) manifest in disease. Diabetes and neurodegenerative disorders such as Alzheimer's and Parkinson's disease share a similar molecular pathology rooted in gut microflora activity. Both of these conditions are associated with a dysbiosis characterized by low species diversity, a higher proportion of pathobionts at the expense of symbionts, an abundance of proinflammatory microbes and fewer butyrate-producing strains. Many of these factors can be ameliorated with Lactobacillus spp. and Bifidobacterium spp. probiotic treatment aimed to reestablish healthy gut microflora diversity. Indeed, certain commensal and pathogenic strains promote chronic low-grade inflammation that stresses cellular infrastructure eventually leading to apoptosis in both the pancreas and the brain. Also, lack of some beneficial fermentation products such as butyrate and ferulic acid initiates a cascade of events disrupting metabolic homeostasis. Finally, signaling initiated by the microflora and its metabolites has been shown to disrupt the delicate intracellular balance of PI3K/Akt/mTOR signaling, which fundamentally regulates events leading up to diabetes and neurodegenerative disease pathogenesis. The following review investigates the relationship between the manifestation and molecular signaling of diabetes and neurodegenerative disorders and how the balance of gut microflora populations is critical to both prevent and possibly treat these diseases.
\end{abstract}

Keywords: Diabetes; Alzheimer's disease; Parkinson's disease; Metabolism; Gut microflora; Lactobacillus; Bifidobacterium; Probiotics; Akt; mTOR

\section{Introduction}

Humans coexist with a vast community of microbial species residing in their gastrointestinal tract (GIT) collectively known as the gut microflora. There are an estimated $10^{13}-10^{14}$ bacterial cells found in the GIT constituting over 1000 species [1,2]. This dense ecosystem constitutes an intimate relationship with the host enabling the digestion of vitamins, minerals and otherwise indigestible fibers while producing signaling factors essential for human health.

The dominant phyla consisting of approximately $90 \%$ of the total gut microflora are the Firmicutes and Bacteroidetes, while other significant phyla include Actinobacteria, Proteobacteria, Fusobacteria, Spirochaetae and Verrucomicrobia [3]. The gut microflora significantly varies between people depending on their diet, antibiotic use and other environmental factors although a set of core physiological properties are maintained [4]. Broadly, people can be characterized into one of three enterotypes that are dominated by the genera Bacteroides, Prevotella or Ruminococcus [5]. These enterotypes are age, gender and region independent and seem to depend on the composition of the diet.

Disease is associated with dysbiosis, the imbalance of gut microflora populations. This includes lower species diversity, reduced number of beneficial microbes (symbionts), exaggerated number of harmful microbes (pathobionts), an increase in pro-inflammatory bacteria and a decrease in butyrate-producing bacteria. These changes broadly impact host physiology especially in response to inflammation, oxidative stress, energy homeostasis, hormonal signaling and intracellular signaling cascades therefore contributing to the pathogenesis of many chronic diseases including diabetes and neurodegeneration (Figure 1).

Diabetes is a globally mounting health and economic concern. Diabetes is the most common metabolic disorder worldwide and an estimated $8.3 \%$ of the global population is currently living with diabetes. Strikingly, incidence rates are ever rising $3-5 \%$ per year $[6,7]$. This immense rise is not fully explained by genetic and obesity-related variations hence causation must be at least partially attributed to other environmental factors including the progressively degenerating health of the intestinal microflora.

Diabetes is characterized by a dysregulation of insulin activity either by reduced production in the pancreas due to an autoimmune response against insulin producing $\beta$-cells (Type-1 diabetes; T1D) or an inappropriate release of insulin in response to glucose levels (Type-2 diabetes; T2D). In either case, insulin desensitization leads to hyperglycemia, a condition that causes severe stress on

*Corresponding author: Satya Prakash, Biomedical Technology and Cell Therapy Research Laboratory, Department of Biomedical Engineering, Department of Experimental Medicine, Faculty of Medicine, McGill University, 3775 University Street, Montreal, Quebec, H3A2B4, Canada, Tel: 1-514-398-3676; Fax: 1-514-3987461; E-mail: satya.prakash@mcgill.ca

Received April 30, 2015; Accepted June 30, 2015; Published July 04, 2015

Citation: Westfall S, Lomis N, Singh SP, Dai SY, Prakash S (2015) The Gut Microflora and its Metabolites Regulate the Molecular Crosstalk between Diabetes and Neurodegeneration. J Diabetes Metab 6: 577. doi:10.4172/2155-6156.1000577

Copyright: ( 2015 Westfall S, et al. This is an open-access article distributed under the terms of the Creative Commons Attribution License, which permits unrestricted use, distribution, and reproduction in any medium, provided the original author and source are credited. 


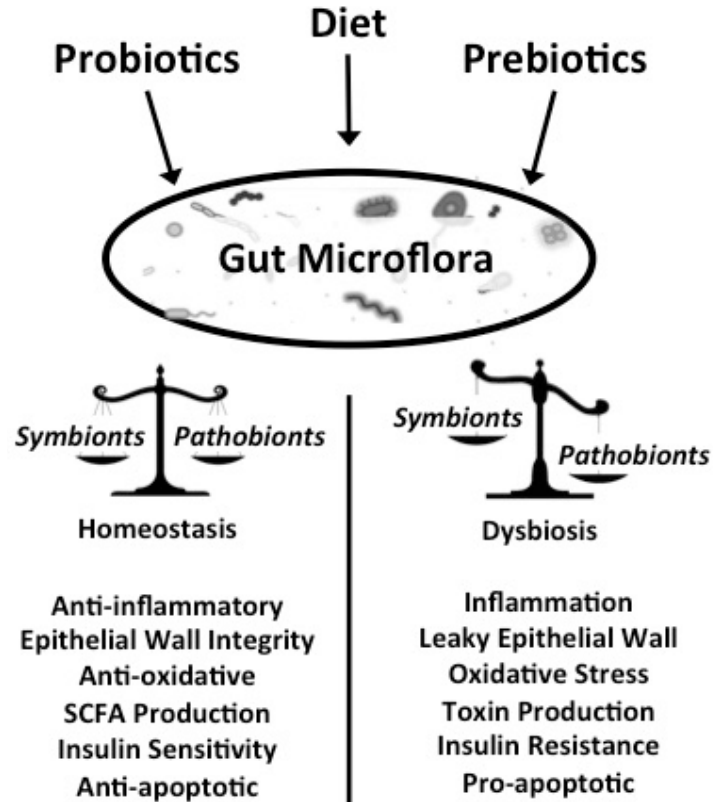

Health

Figure 1: The gut flora has a blanket effect on several aspects of disease development. Diet, probiotics and prebiotics all influence the populations of the gut microflora. Highfat and high-sugar diets negatively impact beneficial microbes leading to dysbiosis characterized by an increase in pathobionts at the expense of symbionts. Probiotics and prebiotics realign gut dysbiosis by promoting a healthy balance of beneficial microbes including butyrateproducing, balancers of energy homeostasis, anti-inflammatory and antioxidative species. Since many chronic diseases have a multi-faceted etiology rooted in inflammation and metabolic distress, the broad action of beneficial gut microflora species is a keen target for reversing the pathogenesis of disease.

physiological systems. There are many players contributing to diabetes disease pathology including chronic low-grade inflammation and endotoxemia, oxidative stress, degradation of insulin signaling factors, impaired intestinal permeability and misregulation of intracellular signaling pathways. Notably, all of these pathways are linked to dietinduced dysbiosis [8].

Chronic peripheral hyperinsulinemia and insulin resistance are the two prominent features of diabetes and both these conditions predispose the brain to damage. Under normal conditions, insulin signaling is neuroprotective and protects neurons from various oxidative, inflammatory and toxic stresses. Considering that insulin found in the brain is from pancreatic origin, it is understandable that in a diabetic state, peripheral insulin resistance is carried over to central insulin resistance and resulting impairments in neuronal growth, differentiation, learning, memory and cognition manifest [9-11].

Neurodegeneration is an age-related progressive cognitive decline manifesting in several devastating neurological deficits from motor impairment to memory loss. Like diabetes, inflammation, oxidative stress, energy homeostasis and dysregulation of intracellular signaling pathways constitute the major pathological features of neurodegeneration. Interestingly, there is significant cross-talk between the molecular signaling cascades of neurodegeneration and diabetes, all of which are linked to the health of the gut microflora.
Alzheimer's disease $(\mathrm{AD})$ is characterized by the progressive loss of memory, motivation, disorientation, cognitive abilities and eventually bodily functions. It is the most common neurodegenerative disease, affecting up to $7 \%$ of people over 60 and $80 \%$ of people over 80 in industrialized countries [12]. Pathologically, $\mathrm{AD}$ is characterized by the accumulation of extracellular amyloid plaques and prion-like intracellular neurofibrillary tangles (NFTs) in the brain that are composed of protein aggregates of amyloid(A) $\beta$ and hyperphosphorylated tau, respectively. Genetic mutations in the amyloid precursor protein (APP) and presenilins (PS) increase the production of $A \beta 42$, a minor form of $A \beta$ that has increased aggregatibility and forms the major part of senile plaques. This plaque accumulation instigates neuronal cell apoptosis from accumulating oxidative stressors and dysregulation of intracellular signaling.

Parkinson's disease (PD) is a multifactorial disease rooted in both environmental and genetic factors and affects $2 \%$ of people over 60 and $5 \%$ of people over 80 , worldwide [13]. It is characterized by the progressive degeneration of dopaminergic neurons in the substantia nigra, a midbrain region. The atrophy of these neurons contributes to the progressive motor deficits characteristic of $\mathrm{PD}$ including progressive shaking, slowness in movement, rigidity, depression, dementia and digestive difficulties. One of the hallmarks of PD is the formation of Lewy bodies and Lewy neurites, insoluble protein aggregates composed primarily of $\alpha$-synuclein.

Diabetes and neurodegenerative diseases are inherently distinct pathologies yet frequently manifest together. The decreased insulin levels and corresponding hyperglycemia in diabetes creates various neurological stresses ultimately leading to disease. Patients with T2D have twice the incidence of sporadic $\mathrm{AD}$ than healthy individuals [14] and about 40\% higher chance of developing PD [15]. In fact, the increased sensitivity of $\mathrm{AD}$ patients to insulin and diabetic markers has coined AD as 'Type 3 Diabetes' [16]. This relationship is not surprising as it has been long known that insulin-like signaling (IIS) and metabolic syndrome leads to premature aging and cognitive deficits [17]. PD patients with diabetes acquire more severe disease manifestations $[18,19]$ and it has been shown that $8-30 \%$ of PD patients develop diabetes, which is significantly higher than the healthy population, and those people acquire more severe PD symptoms [20]. PD patients also experience a much higher incidence of glucose intolerance and insulin resistance, even without a diagnosis of T2D. In PD, insulin resistance is coupled with an increased vulnerability to chemically-induced neuronal damage, exasperated motor deficits and dopamine depletion indicating that T2D compounds PD symptoms [21].

\section{Relationship between Gut Microflora and the Development of Diabetes and Neurodegeneration}

Dysbiosis predisposes, aggravates or even causes diabetes. Diet drastically impacts the composition of the gut microflora evident by the polarity of the diet-dependent enterotypes. This is important as the composition of the gut microflora affects how the body processes energy and extracts calories from food. Likewise, high-fat and highsugar diets alter the microflora populations such that it provokes the underlying pathology of diabetes, namely imbalances in energy homeostasis, circulating glucose levels, apoptosis, proinflammatory and oxidative states.

In $\mathrm{T} 2 \mathrm{D}$, there is an overall loss of gut microbial diversity with an increase in opportunistic pathogens. This includes a decrease in the phyla Firmicutes with a proportionate increase in Bacteroidetes, together with a decrease in butyrate-producing bacteria [22]. 
Citation: Westfall S, Lomis N, Singh SP, Dai SY, Prakash S (2015) The Gut Microflora and its Metabolites Regulate the Molecular Crosstalk between Diabetes and Neurodegeneration. J Diabetes Metab 6: 577. doi:10.4172/2155-6156.1000577

Page 3 of 16

Specifically, Bacteroides vulgatus, Faecalibacterium prauznitzii and the Bifidobacterium and Roseburia genuses are under-represented in diabetic patients $[3,23,24]$. Various species belonging to the Lactobacillus genus are reported to be elevated in diabetic models, however several known probiotic Lactobacillus spp. have also been identified as beneficial in treating diabetes (Table 1). In addition, an increase in fecal levels of Lactobacillus gasseri, Streptococcus mutans and Escherichia coli is predictive of insulin resistance [25]. When insulin-resistant males received lean donor fecal transplantations, there was a significant increase in intestinal microbial diversity and a distinct increase in butyrate-producing bacteria such as Roseburia and Faecalibcaterium spp. in the feces and Eubacterium halii in the small intestine [26]. Not only are gut microbial populations altered in diabetes, but therapeutic interventions to reinstate gut microbial homeostasis has potential to alleviate the associated symptoms.

Certain deficits in beneficial microflora populations are associated with an increased autoimmune response and greater destruction of the insulin producing pancreatic $\beta$-cells. It was shown that reduced Lactobacillus or Bifidobacterium genuses predisposed rat islet cells to autoimmune destruction [27]. Interestingly, an antibiotic

\begin{tabular}{|c|c|c|c|c|c|}
\hline \multirow{2}{*}{ Probiotic } & \multicolumn{5}{|l|}{ Effects on } \\
\hline & Dietary Factors & Insulin Signaling & Inflammation & Molecular Effects & References \\
\hline \multicolumn{6}{|c|}{ Phylum Actinobacteria } \\
\hline $\begin{array}{l}\text { Genus } \\
\text { Bifidobacterium }\end{array}$ & $\begin{array}{l}\downarrow \text { HFD } \\
\downarrow \text { Obesity } \\
\downarrow \text { T2D }\end{array}$ & $\begin{array}{l}\downarrow \text { Plasma glucose } \\
\downarrow \text { Insulin resistance } \\
B \text {. animalis }\end{array}$ & $\begin{array}{l}\text { Anti-inflammatory } \\
\text { B. animalis } \\
\text { B. brevis } \\
\text { B. infantis }\end{array}$ & $\begin{array}{l}\uparrow \text { IRS1 } \\
\uparrow \text { Akt } \\
\uparrow \text { ERK } \\
\uparrow \text { FA (B. animalis) } \\
\uparrow \text { Butyrate } \\
\text { B. brevis, B. infantis, B. } \\
\text { longum) } \\
\uparrow \text { EPAs (B. brevis) }\end{array}$ & {$[23,50,205-210]$} \\
\hline \multicolumn{6}{|l|}{ Phylum Firmicutes } \\
\hline $\begin{array}{l}\text { Genus } \\
\text { Lactobacillus }\end{array}$ & $\begin{array}{l}\downarrow \text { in T2D } \\
\text { L. reuteri } \\
\text { L. acidophilus } \\
\text { L. casei } \\
\text { L. plantarum } \\
\text { L. rhamnosus }\end{array}$ & $\begin{array}{l}\downarrow \text { Plasma glucose } \\
\text { L. reuteri } \\
\text { L. acidophilus } \\
\text { L. casei } \\
\text { L. plantarum } \\
\downarrow \text { Insulin resistance } \\
\text { L. reuteri } \\
\text { L. acidophilus } \\
\text { L. fermentum } \\
\text { L. casei } \\
\text { L. plantarum } \\
\text { L. rhamnosus } \\
\downarrow \text {. } \beta \text {-cell injury } \\
\text { L. plantarum }\end{array}$ & $\begin{array}{l}\text { Anti-inflammatory } \\
\text { L. reuteri } \\
\text { L. acidophilus } \\
\text { L. fermentum } \\
\text { L. casei } \\
\text { L. salivarius } \\
\text { L. plantarum } \\
\text { L. rhamnosus }\end{array}$ & $\begin{array}{l}\downarrow \text { GLP-1 (L. reuteri) } \\
\downarrow \text { GLP-2 (L. casei) } \\
\uparrow \text { FA }(L . \text { reuteri, L. } \\
\text { fermentum) } \\
\uparrow \text { PPARa mRNA ( } L . \\
\text { plantarum) } \\
\downarrow \text { Gluconeogenic genes } \\
\text { (L. rhamnosus) } \\
\uparrow \text { Lactate (all spp.) }\end{array}$ & {$[22,24,43,44,81,211-224]$} \\
\hline $\begin{array}{l}\text { Genus } \\
\text { Bacillus }\end{array}$ & $\begin{array}{l}\uparrow \text { T2D } \\
\text { B. caccae }\end{array}$ & $\downarrow$ Insulin resistance & $\begin{array}{l}\text { Anti-inflammatory } \\
\text { B. caccae } \\
B \text { mesentericus }\end{array}$ & & {$[25,225-227]$} \\
\hline $\begin{array}{l}\text { Genus } \\
\text { Clostridium }\end{array}$ & $\begin{array}{l}\downarrow \text { T2D } \\
\text { Clostridium cluster XIV } \\
\text { Clostridium cluster IV } \\
\text { Clostridium coccoides } \\
\text { Clostridium leptum group } \\
\uparrow \text { T2D } \\
\text { Clostridium difficile }\end{array}$ & $\downarrow$ Plasma glucose & $\begin{array}{l}\text { Anti-inflammatory } \\
\text { C. butricum } \\
\text { Pro-inflammatory } \\
\text { C. difficile } \\
\text { Clostridium cluster XIV }\end{array}$ & $\begin{array}{l}\uparrow \text { Butyrate } \\
\text { Clostridium cluster XIV }\end{array}$ & {$[25,227-234]$} \\
\hline $\begin{array}{l}\text { Genus } \\
\text { Faecalibacterium }\end{array}$ & $\begin{array}{l}\downarrow \text { T2D } \\
\text { F. prausnitzii }\end{array}$ & & $\begin{array}{l}\text { Anti-inflammatory } \\
\text { F. prausnitzii }\end{array}$ & $\begin{array}{l}\uparrow \text { Butyrate } \\
\text { Faecalibacterium } \\
\text { prausnitzii }\end{array}$ & [235] \\
\hline $\begin{array}{l}\text { Genus } \\
\text { Roseburia }\end{array}$ & $\begin{array}{l}\downarrow \text { T2D } \\
\text { Roseburia intestinalis } \\
\downarrow \text { T1DM }\end{array}$ & & $\begin{array}{l}\text { Anti-inflammatory } \\
\text { Roseburia intestinalis } \\
\text { Roseburia faecis }\end{array}$ & $\begin{array}{l}\uparrow \text { Butyrate } \\
R . \text { cecicola, R. intestinalis, } \\
R . \text { hominis }\end{array}$ & {$[22,74,235,236]$} \\
\hline $\begin{array}{l}\text { Genus } \\
\text { Eubacterium }\end{array}$ & $\begin{array}{l}\downarrow \text { T1DM (BBDP mice) } \\
\downarrow \text { T2D } \\
\text { Eubacterium rectale }\end{array}$ & $\begin{array}{l}\downarrow \text { Insulin resistance } \\
\text { E. hallii }\end{array}$ & $\begin{array}{l}\text { Anti-inflammatory } \\
\text { Eubacterium rectale }\end{array}$ & $\begin{array}{l}\uparrow \text { Butyrate } \\
\text { E. rectale, E. ventriosum, } \\
\text { E. hallii }\end{array}$ & [235] \\
\hline $\begin{array}{l}\text { Genus } \\
\text { Ruminococcus }\end{array}$ & $\uparrow$ T1DM (BBDP mice) & & Anti-inflammatory & & {$[27,235]$} \\
\hline \multicolumn{6}{|c|}{ Phylum Bacteriodetes } \\
\hline \begin{tabular}{|l} 
Genus \\
Bacteroides
\end{tabular} & $\begin{array}{l}\downarrow \text { T1DM } \\
\downarrow \text { T2D }\end{array}$ & $\uparrow$ Circulating Glucose & $\begin{array}{l}\text { Anti-inflammatory } \\
\text { B. fragilis }\end{array}$ & & {$[27,226,235]$} \\
\hline $\begin{array}{l}\text { Genus } \\
\text { Prevotella }\end{array}$ & $\begin{array}{l}\downarrow \text { T1DM } \\
\downarrow \text { T2D }\end{array}$ & & Anti-inflammatory & $\downarrow$ Mucin & {$[22,23,74,229,235,237]$} \\
\hline \multicolumn{6}{|c|}{ Phylum Proteobacteria } \\
\hline $\begin{array}{l}\text { Genus } \\
\text { Escherichia }\end{array}$ & $\uparrow$ T2D & $\uparrow$ Insulin resistance & $\begin{array}{l}\text { Pro-inflammatory } \\
\text { E. coli k88 } \\
\text { Anti-inflammatory } \\
\text { E. coli Nissle }\end{array}$ & & {$[22,23,74,236,237]$} \\
\hline
\end{tabular}

Table 1: The role of gut microflora and their metabolites in diabetes, insulin signaling and inflammation. 
therapy regime coupled with a hydrolyzed casein diet prevented islet destruction through mechanisms involving the gut microflora [28]. These studies demonstrate how the gut microflora protect the cellular integrity of pancreatic $\beta$-cells, insulin production and the fundamental root of diabetes.

In neurodegenerative diseases, there are similar changes in the gut microflora. Like diabetes, $\mathrm{AD}$ and $\mathrm{PD}$ are associated with a general loss of microbial diversity $[29,30]$ and shifts in the proportion of the dominant phyla, Firmicutes and Bacteroides. Up to $80 \%$ of PD patients suffer from GI dysfunctions linked to poor health of the gut microflora [31] and these GI effects are likely causative to disease development. There is also an overall increase in the pathobionts at the expense of symbionts characterized by an increase in Proteobacteria and other pro-inflammatory species with a decrease in Bifidobacterium [29,30,32] and Prevotella [33]. There have been several studies in germ-free mice investigating the impact of the microflora and specific probiotic treatments on neurological protection in aging. Several Lactobacillus (i.e. L. helveticus, $L$. rhamnosus, $L$. fermentum, $L$. plantarum, $L$. reuteri, L. acidophilus) and Bifidobacterium (i.e. B. animalis, B. breve. B.longum) probiotics that affect inflammatory and oxidative pathways also influence the production of neurotropic factors that ultimately provide protection against the onset of degeneration [34-36].

There are also several species that directly communicate with the vagal afferents in the enteric nervous system to directly effect neuronal activity in the brainstem. L. reuteri, L. rhamnosus and Bacteroides fragilis all activate vagal afferent signaling [37,38]. This is critical especially for PD development as vagal stimulation in the dorsal motor nucleus of the vagus (DMV) is one of the earliest affected regions for the accumulation of central $a$-synuclein pathology. Indeed, the microflora-produced metabolites propionate and butyrate also communicate with the brain in a vagal-dependent manner influencing DMV gluconeogenesis, cholinergic neuronal signaling (implicated in AD) and anti-inflammatory pathways [39].

Gut dysbiosis can be ameliorated by prebiotic or probiotic treatment. Prebiotics were shown to increase the level of species in the Bifidobacterium genus, an effect that positively correlates with improved glucose-tolerance, glucose-induced insulin secretion and reduced inflammatory markers [40,41]. In a diabetic-prone rat model (BioBreeding diabetes-prone rat; BBDP), transplantation of the probiotic $L$. johnsonii into the host ileum delayed disease progression by regulating the anti-inflammatory $\mathrm{Th} 17$ cell response [42]. L. acidophilus and $L$. casei probiotic therapy was also shown to elicit concatenate decreases in endotoxemia and oxidative stress markers in a diabetes rat model $[43,44]$. The potential benefit of probiotic treatment in multifaceted chronic diseases is immense as several disease pathways are simultaneously affected unlike conventional medicines where only one specific pathway is targeted.

\section{Gut Microflora affects Inflammatory State in Diabetes and Neurodegenerative Disease}

Chroniclow-grade inflammation and endotoxemia are major causes of age-related diseases and has recently been coined 'inflammaging' [45]. Many inflammatory pathways are dually implicated in both diabetes and neurodegeneration and are rooted in the dysbiosis of the gut [46]. There is ample evidence and several reviews have been written outlining the link of low-grade inflammation to T2D and AD so it will only be briefly outlined below $[47,48]$.

Gut microbes, through lipopolysaccharide (LPS) and other surface signaling molecules, stimulate Toll-like receptors (TLRs) on innate immune cells initiating an inflammatory cascade by the cytokine-promoting actions of NFkB [49]. The high-fat mediated alterations to the gut microflora are correlated with a two-three fold increase in circulating LPS and a state of metabolic endotoxemia [50]. These inflammatory changes are inhibited by both TLR- 4 knockout and antibiotic treatment against pro-inflammatory microbes [51] indicating the importance of the gut microflora in instigating dietinduced inflammatory signals. Supporting this, TLR-4 stimulation by Gram-negative bacteria is critical for the development of high-fat diet induced insulin resistance [52] and siRNA-mediated knock-down of TLR-4 suppresses inflammation and insulin resistance triggered by LPS $[53,54]$.

An alteration to the gut microflora by probiotic or prebiotic intervention is linked to reduced gut-induced inflammation. In particular, Lactobacillus and Bifidobacterium species are known to have potent anti-inflammatory actions (Table 1). In vitro, the gut supernatant from Bifidobacterium infantis ATCC 15697 was shown to reduce the release of TNFa and increase IL- 4 concentrations secreted by macrophages [55]. In addition, there have been many animal and human trials investigating the role of probiotics in reducing inflammatory markers. One famous combinatorial probiotic VSL\#3 that contains four strains of Lactobacilli, three strains of Bifidobacteria and one strain of Streptococcus has shown great anti-inflammatory potential [56,57]. Refer to Table 1 for more specific evidence of the anti-inflammatory action of probiotics.

Low-grade chronic systemic inflammation contributes to the development of insulin resistance, diabetes and obesity [58,59]. In both nonobese diabetic (NOD) and BBDP mice, certain probiotic and antibiotic regimes are effective in protecting mice against the onset of diabetes. These changes are correlated with marked changes in the gut microbial communities, partially attributed to the decrease in inflammatory markers [28]. In T2D, the majority of inflammation is derived in the adipose tissue from the activation of immune cells, possibly from the gut microflora. In humans, chronic low-grade endotoxemia increases the adipocyte release of cytokines promoting NFkB expression and insulin resistance [60]. It was later shown that gut-derived inflammation is linked to mechanisms of islet destruction [61]. The actual mechanisms of insulin resistance in the key tissues involved in diabetes (muscle, liver, adipose tissue) remain unknown, but it is certain that these mechanisms interact with inflammatory signaling from diet, obesity and the gut microflora.

To demonstrate the importance of TLR signaling in diabetes, the knock-out of MyD88 (a key intracellular adapter molecules mediating TLR signaling) protected NOD mice from diabetes onset and decreased the autoimmune reaction against pancreatic $\beta$-cells in a microbedependent manner. Indeed, MyD88 depletion is associated with a lower Firmicutes to Bacteroidetes ratio and an increased proportion of Lactobacilli, Rikenellae and Porphyromonadaeae [62].

There is no mystery that neurodegenerative diseases are highly correlated with systemic inflammation. In the PD brain, aggregation of proinflammatory factors with $\alpha$-synuclein aggrevates the progression of dopaminergic cell death [63]. Indeed, direct injection of LPS into the brain will destroy dopaminergic neurons implicating a direct role for inflammation in neurodegeneration [64]. Similarly in AD, amyloid plaques activate various caspases and secondary signalers like NFkB and activator protein (AP)-1, which consequently amplify the cytokine proinflammatory response and induce apoptosis [65]. In addition, low-grade inflammation aggravates cognitive impairment 
and proinflammatory cytokines co-aggregate with plaques and NFTs further promoting their neurotoxicity [66]. Finally, the neuroprotective ApoE protein is anti-inflammatory and was found to attenuate the $A \beta$ plaque induced glial activation indicating the importance of mimizing neuroinflammation in the protection against $\mathrm{AD}$ [67].

The integrity of the gut intestinal barrier is critical to prevent an unprecedented pro-inflammatory response. Following this, diabetic animals have been shown to have compromised intestinal barrier integrity. In mice fed a high-fat diet, there is a reduction in the expression of tight-junction proteins including occudin and $\mathrm{ZO}-1$ thereby increasing gut wall permeability and circulating LPS levels [50]. In NOD and BBDP mice treated with probiotics, there is an increase in the tight-junction protein claudin coupled with reduced systemic inflammation outlining the importance of gut-derived action on mucosal barrier wall functionality in diabetes associated inflammation $[28,42,68]$. One study also identified that gut-microflora-mediated epigenetic changes to the TLRs in the gut epithelium could regulate the immune response affecting the diabetic phenotype [69]

\section{Microflora-derived SCFAs Impact Diabetes and Neurodegeneration}

Short-chain fatty acids (SCFAs) are the products of gut microbial fermentation of otherwise indigestible fibers. The SCFAs including propionate, acetate and butyrate are pertinent to regulating host energy metabolism, inflammatory state and levels of oxidative stress [70]. Butyrate interacts with the epithelial cells and provides energy whereas propionate and acetate enter the portal venous system and elicit more systemic effects. For example, propionate regulates hepatic lipogenesis and gluconeogenesis where acetate acts as a substrate for cholesterol synthesis [71]. In contrast, butyrate is associated with more anti-inflammatory actions via the inhibition of NFkB [72].

\section{Butyrate}

Butyrate preserves the integrity of the intestinal epithelial barrier, which is critical to prevent LPS-containing Gram-negative bacteria from transiting across the epithelial layer and initiating a systemic immune response [70]. To do this, butyrate increases the production of epithelial mucin, enhancing cell wall integrity [46]. Butyrate also activates GPR109A a signaling molecule expressed on the surface of intestinal epithelial cells associated with downregulating NFKB signaling and suppressing TNFa, IL- 6 and IL-1 $\beta$ activation [46]. In humans, oral butyrate is beneficial in Crohn's disease and ulcerative colitis indicating its potent anti-inflammatory action in inflammatory conditions [73].

As previously mentioned, diabetic patients have reduced levels Gram-positive butyrate-producing bacteria likely contributing to their disease pathology [74]. In T2D patients, there was a decrease in the butyrate Clostridiales bacteria (Roseburia and F. prausnitzii) with a greater amount of non-butyrate producing Clostridiales and pathogens such a C. clostridioforme [25]. Indeed, reduced butyrate is associated with endotoxemia, inflammation and the development of insulin resistance in mice [49]. To show this, mice supplemented with oral butyrate have improved insulin sensitivity and an increase in energy expenditure evidenced through improved mitochondrial function [75].

Butyrate also plays a role in protecting against neurodegenerative diseases. The mechanism is not fully elucidated however the histone deacetylase (HDAC) inhibiting activity of butyrate is deemed to be one factor. Recently, HDAC inhibitors have been linked to neuroprotective and neuro-regenerative roles in animal models of neurodegenerative diseases [76]. Indeed, amyloid pathology is correlated to a pronounced dysregulation of histone acetylation in the forebrain of an $\mathrm{AD}$ mouse model. Even when administered at a late stage of $\mathrm{AD}$ development, sodium butyrate improved memory impairment in these mice [77]. In $\mathrm{PD}$, sodium butyrate was shown to alleviate pre-motor cognitive deficits in a 6-OHDA PD mouse model [78]. In another study, sodium butyrate reduced the degeneration of dopaminergic neurons in a mutant $\alpha$-synuclein model of PD in Drosophila melanogaster. Further, sodium butyrate rescued the motor deficits, early mortality and loss of dopamine expression in the brain of rotenone-treated PD mice [79]. Although not thoroughly researched, the anti-inflammatory action of butyrate would also be protective against both $\mathrm{AD}$ and $\mathrm{PD}$.

\section{Ferulic acid}

Ferulic acid (FA) is an organic phenolic phytochemical naturally found in coffee, apple seeds, peanuts, rice, wheat and oats. It is also prominent in some Chinese and Indian medicines, namely the Chinese water chestnut (Eleocharis dulcis) and hing (asafoetida), respectively [80]. FA is a potent free radical scavenger, anti-apoptotic agent and anti-inflammatory agent. From the gut, FA is naturally produced via the intrinsic ferulic acid esterase (FAE) activity of select microbes including various species of Lactobacillus [81].

In various diabetes mouse models, FA works via several mechanisms to reduce blood glucose and increase plasma insulin levels [82]. In rats induced with diabetes, FA significantly improved blood glucose levels and oxidative status in the pancreatic tissues [82], to a similar extent as other oral anti-diabetic drugs such as metformin and thiozolidinediones (TDZs) [83]. In leptin deficient $d b /$ $d b$ mice, FA increased plasma insulin, lowered blood glucose, increased hepatic glycogen synthesis and the upregulated the activity of the glucoceogenesis gene glucokinase [84]. FA extracted from Hibiscus leaves prevented insulin resistance by protecting insulin receptor integrity [85]. Applied daily for 8 weeks to Zucker diabetic fatty rats, a model of hyperlipidemia and hyperglycemia, the FA-producing L. fermentum reduced fasting insulin levels and insulin resistances indicating that the FA produced from probiotic bacteria is sufficient to improve conditions of diabetes [86].

FA reduces the harsh pro-oxidant conditions of neurodegeneration, diabetes and cardiovascular disease by restoring antioxidant gene and Hsp70 expression [80]. The main targets of FA in preventing oxidative damage include superoxide dismutase (SOD) and catalase (CAT); two enzymes critical to detoxify superoxide anions. In streptozotocin-induced diabetic rats, FA restored SOD and CAT levels in the myocardium and pancreatic tissue $[82,87]$ while simultaneously reducing inflammatory markers and apoptosis in pancreatic $\beta$-cells [82]. Interestingly, FA in combination with fish oil was shown to reduce several oxidative markers, improve cognitive state and improve levels of dopamine [88] and other neurotransmitters in a 3-nitropropionic acid model of neurological damage [89].

In the brain, FA provides several neuroprotective effects including anti-inflammatory and anti-oxidant functions [80]. In neurons, FA inhibits peroxyl radical induced apoptosis and at higher doses prevented protein and lipid oxidation [90,91]. Indeed, in a glutamate toxicity model, FA completely inhibited apoptosis and the elevated caspase 3 and reduced Bcl2 levels [92]. In a rat model of cerebral ischemia, FA prevented apoptosis and iNOS induction, indicating that it is protective against external assaults. In aging rats, sodium ferulate supplementation counteracted the age-related increase in proinflammatory cytokines [93]. 
In several contexts, FA has been shown to directly alleviate $\mathrm{AD}$ pathology. FA dissolves $A \beta$ plaques therefore preventing its toxicity both in vitro and in vivo $[94,95]$. In a transgenic $\mathrm{AD}$ mouse model, FA reversed memory deficits, decreased $\beta$-amyloid plaque deposits and reduced $\beta$-secretase activity and the consequent production of toxic $A$ fragments. Alsoin thisstudy, FA treatment wasassociated with attenuated neuroinflammation and reduced oxidative stress [96]. After injection of $\mathrm{A} \beta$, FA treatment ameliorated IL- $1 \beta$ production, neuroinflammation and restored memory loss [94]. Similar anti-inflammatory and $A \beta$ deposition reduction was noted in a transgenic APP/PS mouse model of $\mathrm{AD}$ coupled with enhanced cognitive performance [97]. FA was shown to directly inhibit the memory impairment of $A \beta 1-40$ induced $A D$ in rats while reversing the deterioration of anti-oxidative factors. FA also rescued the compromised acetylcholine esterase activity characteristic of the AD phenotype [98]. These effects are likely administered by the combined anti-inflammatory, anti-oxidative and enhanced choline acetyltransferase activity of FA [99].

Heat shock protin (Hsp)70 is a family of chaperone proteins that are strongly upregulated in response to stress and inflammation, which ultimately protect cellular integrity by supporting proper protein folding. In diabetes, the imbalance in the extracellular to intracellular Hsp70 can trigger a proinflammatory state and insulin resistance aggravating T2D development [100]. In neurodegenerative diseases, the accumulation of protein aggregates $(A \beta$ in $A D$ and $\alpha$-synuclein in PD) is a principle pathology and HSPs have been found to be colocalized to these aggregates. Further, upregulation of Hsp70 (and other chaperones) can trigger the solubilization of protein aggregates both preventing and treating neurotoxicity. Hence, regulation of Hsp70 may be beneficial for both diabetes and neurodegeneration. In this context, FAE was shown to upregulate Hsp70 in rat cortical neurons and prevented ROS and $A \beta$-induced neurotoxicity [101] indicating the functional ability of FA to regulation $\mathrm{Hsp} 70$ levels.

\section{Impact of Insulin, IGF-1 and GLP-1 Signaling in Neurodegenerative Disease}

Insulin-like signaling (IIS) promotes many cell-protective and growth promoting pathways. In a healthy state, insulin signaling promotes neurogenesis in the CNS including synaptic maintenance, dendritic sprouting, cell growth, repair and neuroprotection $[102,103]$.

Both the insulin receptor and the IGF-1 receptor, upon being activated by their respective ligand, undergo autophosphorylation and expose docking sites for the insulin receptor substrate (IRS). IRS binding and activation initiates a cascade of phosphorylation events beginning with phosphoinositide 3-kinase (PI3K) and Akt. Akt phosphorylates and largely inactivates its many targets that are proapoptotic (such as GSK3 $\beta$ ) and proinflammatory (such as NFkB). Akt also phosphorylates and inactivates the Forkhead box (FOX)O transcription factor that subsequently promotes apoptosis. Finally, Akt also acts on p70s6k, a kinase that feedbacks back onto IRS-1/2 preventing its over-activation. These factors and others will be described in more detail below and how their regulation is important in the mutual regulation of diabetes and neurological disease.

In both $\mathrm{PD}$ and $\mathrm{AD}$, fundamental insulin signaling is impaired in the brain exacerbating neurological damage [102]. Cellular insulin signaling impacts numerous molecular cascades affecting apoptosis, production of inflammatory mediators, oxidative damage and others. In particular, there is evidence that insulin signaling directly implicates the specific proteinopathies of PD and AD.

In $\mathrm{AD}$, IlS regulates the metabolism of amyloid $\beta$ plaques and tau proteins $[47,104,105]$. There is a strong colocalization of NFTs with the phosphorylated (and inactivated) IRS-1/2 receptors [106] directly associating diabetes pathology with exasperated AD. Also, the levels of phosphorylated IRS at its inhibitory residue are positively correlated with the concentration of $A \beta$ plaques and NFTs and negatively associated with intracellular PI3K and Akt signaling activation $[107,108]$. The converse is also true, A aggregates have been suggested to trigger the removal of insulin receptors from the plasma membrane in cultured neurons further aggravating AD pathogenesis $[109,110]$.

In $\mathrm{PD}$, reduced IIS suppresses $\alpha$-synuclein misfolding and neurotoxicity [17]. In the reverse, $\alpha$-synuclein also interferes with the cytoprotective insulin signaling pathways by inhibiting protein phosphatase $2 \mathrm{~A}$ activity, which protects insulin signaling. Overexpression of $\alpha$-synuclein increases IRS-1 phosphorylation, reducing Akt and mTOR signaling, the latter which negatively regulates IRS-1 activity through S6K activity [111]. In the 6-OHDA model of PD in rats, there is severe striatal dopamine depletion manifesting in PD symptoms. In this model, there is a strong depletion of IRS coupled with increased inhibitory phosphorylation of the remaining receptors [112]. Also, silencing of PINK1 and Parkin, two key loss-of-function mutations in familial PD, increases the phosphorylation levels of the IGF-1 receptor impacting the downstream Akt and GSK3 $\beta$ signaling and aggravating PD pathology [113].

\section{Insulin-like growth factor}

Insulin-like growth factor (IGF) 1 is a hormone with similar structure to insulin, however IGF signaling leads to fewer metabolic effects and more greatly influences growth and proliferation. IGF release from the liver is controlled primarily by insulin hence IGF is also reduced in patients with diabetes. Activation of the IGF-1 signaling cascade potently induces Akt signaling pathways, a stimulator of cell growth and proliferation (see below). Clearly, reduced levels of IGF1 signaling in diabetes would have detrimental effects on pancreatic $\beta$-cell survival as well as neuronal cell integrity.

\section{Glucagon-like peptide}

Glucagon-like peptide (GLP) is secreted primarily from the L-cells in the intestinal epithelial layer in response to dietary factors and indigestible fibers. Gut microbiota fermentation of prebiotics promotes L-cell differentiation in the proximal colon of rats and can upregulate the GLP-1 response up to two-fold in response to a meal in healthy humans [49,114]. Increased levels of Lactobacillus and Bifidobacterium species in the gut increase the secretion of GLP-1 from the intestinal L-cells in rats, preserve intestinal wall integrity, reduce endotoxemia, improve glucose-stimulated insulin secretion and lower oxidative markers $[49,50]$. The converse is also true as genetic or pharmacological deletion of GLP-1 prevents the beneficial effects of prebiotics on weight gain, glucose metabolism and inflammatory pathway activation.

GLP is paramount for the incretin effect: the secretion of insulin in response to an oral glucose load. GLPs coordinately induce the glucose-dependent secretion of insulin, suppression of glucagon secretion while in parallel increase insulin sensitivity. In T2D patients, the incretin effect is reduced or even absent. To date, there are several incretin-based therapies (GLP-1 agonists) and the most popular are exenatide and liraglutide [115].

\section{Diabetes-related treatments effective in treatment of neurological disorders}

Many therapeutic strategies targeted to control glucose utilization 
in T2D also protect against neurological damage in AD and PD [116119]. For example, nasal application of insulin improved mild cognitive impairment and reinstated the proper $A \beta 1-40 / 1-42$ ratio in the CSF of $\mathrm{AD}$ patients [120]. The subcutaneous administration of liraglutide, a GLP-1 receptor agonist that improves glucose homeostasis, also ameliorated $\mathrm{AD}$-associated tau hyperphosphorylation in rats with T2D [121,122]. In a model of age-related sporadic AD, liraglutide lead to significant memory retention, prevented the development of phosphorylated tau and $A \beta$ plaques and increased the total hippocampal neuron count indicating that this GLP-1 agonist not only prevents protein aggregates, but targets multiple aspect of $\mathrm{AD}$ pathology [123]. Exendin-4 is another GLP-1 agonist and when administered to mice with T2D, significantly reduced tau phosphorylation while upregulating brain IIS [124].

Similar effects were also reported in the 6-OHDA and LPS models of PD. Exendin- 4 protected PD mice against loss of dopaminergic neuronal transmission, tyrosine hydroxylase activity and rescued motor function effectively preventing and even reversing the functional impairment in PD [125]. Likewise, in the MPTP toxin model of $\mathrm{PD}$, Exendin-4 protected neurons against degeneration, preserved dopamine levels and improved motor function [126].

The association between therapeutic potential of diabetes and neurodegenerative disease is strong, indicating that there are deeply interconnected molecular signaling pathways between these pathologies. As will be investigated below, many of these pathways are related to the gut microflora and can be ameliorated by correcting dysbiosis in these populations.

\section{PI3K/mTOR/Akt Signaling Intersects Diabetes and Neurodegenerative Disease}

The PI3K/Akt/mTor signaling axis is integral to most chronic age-related diseases including diabetes and neurodegeneration. In particular, normal aging critically depends on the tight regulation of these pathways, whose major input is insulin and IGF signaling [108].

\section{Akt}

Akt (protein kinase B) is a master regulator pivotal to the signaling network controlling glucose homeostasis, metabolism, apoptosis, cell growth and survival in response to insulin signaling. Deletion of Akt or the PI3K subunit in mice leads to the development of insulin resistance and T2D [127] and hepatic inactivation of these factors is sufficient to produce hyperglycemia and hyperinsulinemia (rev in[128]). Akt phosphorylates AS160 causing it to dissociate from the insulin-responsive isoform of the glucose transporter GLUT4 located in intracellular storage vesicles, which facilitates its exocytosis to the plasma membrane. In this regard, Akt removes glucose from circulation and reduces hyperglycemia [129]. Akt also phosphorylates CRTC2, a CREB co-activator, that increases hepatic gluconeogenesis hence controlling the release of de novo glucose into the blood [130]. Akt also instigates a feedback regulation on the IRS. PDK1, the activator of Akt, phosphorylates and activates p70S6k, which consequently phosphorylates IRS inhibiting its activity (Figure 1).

In terms of cell survival, Akt phosphorylation inactivates several proapoptotic proteins including Bad and GSK3 $\beta$ [131]. This pathway is evidenced in models of cerebral ischemia where PI3K/Akt activation suppresses pending neuronal cell death eliciting cell survival [132]. Even in PD, the ratio of active phosphorylated Akt to total Akt is reduced indicating that loss of active Akt leads to cellular degeneration [133].
The gut microflora also plays a role in regulating Akt signaling. The lipoteichoic acid (LTA) cell component on Gram-positive cell walls (similar to LPS on Gram-negative bacteria) activates Akt signaling and consequently downregulates GSK3 $\beta$ [134]. Further, many pathogenic bacteria interact with the Akt/GSK3 $\beta$ pathway to induce inflammation (rev in [135]). More specifically, when mice are fed the prebiotic oligofructose (a known enhancer of Bifidobacterium spp. populations), Akt and IRS activity were dually upregulated in a GLP-1-dependent manner [136]. Otherwise, the probiotic L. rhamnosus releases several peptides including p75 and p40 that act through the Akt and PI3K pathways to induce growth and cellular proliferation [137]. Finally, $B$. breve binds to immune cells and activates important downstream pathways through the TLR-2 receptor including PI3K and GSK3 $\beta$ [138]. Thus, not only does the gut microflora impact insulin and glucose signaling directly, it also modulates its action downstream by regulating its intracellular signaling.

\section{mTOR}

The mammalian target of rapamycin (mTOR) is another signaling hub intersecting diabetes and neurodegeneration. mTOR is a nutrient and energy sensor and broadly affects many biochemical processes including translation, autophagy, transcription, cell growth and lipid synthesis (Figure 1).

mTOR1 is a delicate regulator of glucose metabolism and diabetes development. Molecularly, mTOR is activated by nutrients and growth factors but also through insulin signaling via the PI3K/Akt pathways. mTOR1 phosphorylates and activates S6K1, which regulates insulin signaling via a negative feedback loop involving inhibitory IRS-1 phosphorylation and eventual insulin resistance [139]. Likewise, the sustained activation of $\mathrm{mTOR}$ signaling in the $\mathrm{AD}$ brain was reported to cause IRS-1 inhibition, disabling normal activation of PI3K/Akt by insulin [140]. In one study, the deletion of S6K improved insulin resistance, enhanced IRS gene expression and prevented diabetes in mice [141]. mTOR1 activity has also been associated with promoting glucose uptake by upregulating GLUT4 expression [142].

mTOR activation through GLP-1 agonists promotes pancreatic $\beta$-cell proliferation via $S 6 \mathrm{~K}$ activity and prevents neural apoptotic cell loss in T2D [143]. Likewise, rapamycin, the inhibitor of mTOR inhibits $\beta$-cell proliferation and induces $\beta$-cell apoptosis in obese animals by inhibiting glucose-stimulated insulin secretion [144]. There are some studies in which chronic treatment with rapamycin lead to insulin resistance, glucose intolerance and the development of diabetes [145] and where S6K1 deficient mice became hypersensitive to insulin [146]. This is attributed to the long-term effects of mTOR1 signaling and its effects on $\beta$-cell integrity. Chronic mTOR1 activation by glucose impairs IRS signaling which over time induces $\beta$-cell insulin resistance ultimately leading to $\beta$-cell failure $[147,148]$. In addition, as insulin signaling itself is a regulator of mTOR1, extensive insulin inhibition with consequently downregulates mTOR, reduces the protective mTOR signaling and insulin resistance featured in T2D [149]. Ultimately, the response to mTOR 1 is biphasic: initially mTOR 1 increases $\beta$-cell production and reduces insulin resistance while over time, chronic mTOR1 activation induces insulin resistance and hyperglycemia ultimately proving toxic to pancreatic $\beta$-cells [148].

In the CNS, mTOR plays a critical role in maintaining functionality, plasticity, metabolism and response to stress in post-mitotic neurons [108]. Of particular importance, mTOR is pinnacle in the regulation of proteostasis, the overall folding of cellular proteome, by regulating the balance of translation and autophagy. This regulatory process is key to 
prevent the accumulation of toxic protein aggregates such as $\mathrm{A} \beta$ in $\mathrm{AD}$ and $\alpha$-synuclein in PD $[108,150]$. Likewise, hyper phosphorylation and enhanced mTOR activity has been demonstrated in the early stages of $\mathrm{AD}$ [151]. Indeed, there are concatenate increases in the downstream factors activated by mTOR including 4EBP, p70S6K and GSK3 $\beta$, the latter which implements tau phosphorylation and NFT pathology (see below) [152]. In post mortem AD brains, there are also elevated levels of phosphorylated mTOR along with increase expression of its downstream effector, p70S6K [153]. Another study noted that rats induced to have both $\mathrm{T} 2 \mathrm{D}$ and $\mathrm{AD}$ had significantly higher memory impairment and tau protein hyperphosphorylation than those with either AD or T2D alone. Further, mTOR was reportedly hyperphosphorylated in both groups and it was proposed that the overactivation of mTOR in T2D and the corresponding impaired insulin signaling in the hippocampus increased tau phosphorylation and the prevalence of $\mathrm{AD}$ [154].

mTOR plays a similarly important role in PD pathogenesis, however in PD, there is a downregulation of mTOR activity, which leads to oxidative stress, locomotor abnormalities and mitochondrial dysfunctions [155]. Likewise, PD mimetics (6-OHDA, rotenone and MPTP) all reduced mTOR phosphorylation (by reducing Akt activity) while activating apoptotic pathways, an effect rescued with overexpression of mTOR, S6K or 4EBP [156]. Clearly mTOR plays many critical roles in CNS health and maintenance and its regulation remains highly sensitive between promoting healthy and disease states.

Linking mTOR to the microflora it was shown in Drosophila melanogaster that one of its commensal bacteria, Lactobacillus plantarum was sufficient to reinstate a nutrient-rich signaling environment, even in an actual environment of starvation. This control of hormonal growth signaling upregulated mTOR and Akt signaling thus protecting the flies against aging [157]. It is not surprising that the microflora directly impact mTOR signaling considering that mTOR is a nutrient sensor and the gut microflora control nutrient availability to the host.

\section{FOXO}

Forkhead box proteins of the O class (FOXO) are transcription factors that regulate pro-apoptotic genes, proliferation, autophagy, metabolism, inflammation and stress resilience [158]. FOXO inactivation depends on insulin signaling through the PI3K/Akt pathways where phosphorylation of FOXO by Akt relocalizes FOXO from the nucleus to the cytoplasm initiating its degradation. FOXO is an important transcriptional regulator of a conserved insulin response element (IRE: CAAAACAA) present in the promoters of several genes involved in glucose metabolism. These include the two rate-limiting enzymes for gluconeogenesis: phosphoenolpyruvate carboxykinase (Pepck) and glucose-6-phosphatase (G6P) [159]. Indeed, FOXO activation is necessary and sufficient for induction of hyperglycemia following insulin resistance or in T2D (rev in [128]).

FOXO is activated by IIS and many of the longevity-enhancing effects of inhibited IlS is mediated by FOXO [150]. In diabetes, FOXO integrity is required to maintain proper glucose homeostasis and FOXO knockouts protect high-fat fed mice from developing T2D [160]. Notably, mice that overexpress FOXO1 have an impaired ability to regulate blood glucose levels [161]. FOXO also increases the expression of insulin-sensitizing genes, including the peroxisome proliferator-activated receptors or PPARs (see below) [162]. FOXO may transcriptionally repress the PPAR $\gamma$ promoter and possibly even repress PPAR $\gamma$ activity on the protein level [163]. FOXO also negatively regulates mTOR expression through the transcriptional upregulation of glutamine synthetase and AMPK upregulation [164,165].

In normal conditions, FOXO protects cells against oxidative stress and apoptosis [166] including preventing apoptosis in pancreatic $\beta$-cells [167]. FOXO transcribes SOD in the mitochondria (MnSOD), CAT and peroxiredoxin III removing superoxide radicals and oxidative stress associated with diabetes and neurodegenerative disease [168]. Under stressful conditions, such as extreme oxidative stress in diabetes or neurodegeneration, FOXO rather promotes cell death and can further increase ROS production [169]. The ability of FOXO to help cells cope with oxidative damage has made FOXO an important protective factor in the development of neurodegenerative disease. Indeed, the age-related FOXO expression has been related to the development of $\mathrm{A} \beta$ plaques and $\mathrm{AD}$ pathology both through its regulation of oxidative state and even direct regulation of $A \beta$ plaque formation. One of the major mechanisms in the age-related decline of FOXO activity is the corresponding reduction in Hsp70 levels and autophagy, allowing proteotoxicity to grip neurons and lead to apoptosis [170].

Active FOXO creates a proinflammatory environment by transcribing proinflammatory cytokines (IL-1 $\beta$, TLR4). High glucose, TNF and the LPS found systemically or on the cell walls of Gram-negative bacteria can activate the transcriptional activity of FOXO [169]. In connection to diabetes, LPS inhibits the ability of insulin signaling to inactivate FOXO activity, which may explain the exaggerated inflammatory response coupled with insulin resistance $[171,172]$. Akt provides an internal negative feedback regulation in FOXO-mediated inflammation. Although LPS increases FOXO activity, LPS also activates Akt, which in turn inhibits FOXO activity limiting its inflammatory action [173]. Also as previously described, mTOR feeds back to inhibit FOXO activation perpetuating the selflimiting inflammatory cycle [165].

In $\mathrm{PD}$, dopaminergic neurons are sensitive to the levels of FOXO. Likewise, in a recent profiling study, FOXO1 expression and its respective transcriptional targets were found upregulated in the prefrontal cortex of PD patients [173]. Constitutive activation of FOXO is proapoptotic while inhibition of FOXO leads to enhanced oxidative damage. However in the context of PD, mild FOXO activity prevented the accumulation of $\alpha$-synuclein while complete inhibition was shown protective by preventing apoptosis [174]. In fruit flies, expression of the FOXO analog chico reduced lifespan and increased a-synuclein turnover [175]. Further, it was shown that FOXO activation ameliorated PINK1 loss-of-function mitochondrial damage and loss of dopamine in a Drosophila melanogaster model of PD indicating its potent neuroprotective effects [176].

\section{Glycogen synthase kinase $3 \boldsymbol{\beta}$}

GSK3 $\beta$ was originally identified for its ability to inhibit the activity of glycogen synthase and insulin receptors. In response to high levels of circulating glucose, GSK3 $\beta$ phosphorylates and triggers the ubiquitinylation and degradation of IRS1 promoting insulin resistance [177]. It was also found that GSK $3 \beta$ promotes gluconeogenesis in the liver thus aggravating hyperglycemia [178]. In diabetes, GSK3 $\beta$ expression is enhanced exasperating these detrimental effects. Competitive inhibitors of GSK3 $\beta$ increase glucose tolerance in mice as inhibited GSK3 $\beta$ activity should mirror the signaling action of insulin in diabetes by reducing glucose production and enhancing glucose storage. Likewise GSK3 $\beta$ inhibitors have been suggested as therapeutic targets for T2D [179].

Insulin signaling inhibits GSK3 $\beta$ activity through the PI3K/Akt 
signaling pathway. In a T2D mouse model, Exendin-4, the GLP-1 agonist, leads to the corresponding rise of PI3K/Akt signaling in the hippocampus and decline of GSK3 $\beta$ indicating the protective effects of GSK3 $\beta$ in diabetes [124]. GSK3 $\beta$ also phosphorylates and inactivates glycogen synthase-2, which reduces glycogen synthesis in muscle. This inhibition also leads to the activation of mTOR and S6K, which promote protein synthesis and cell growth [180].

GSK3 $\beta$ plays a significant role in neuroinflammation and neurodegeneration. GSK3 $\beta$ actually impacts many aspects of neurodegenerative development including inflammation, apoptosis, neurotransmitter receptor signaling, oxidative stress, taupathy, mitochondrial health and more (rev in [181]). In AD, GSK3 $\beta$ activity is significantly increased likely due to the ensuing insulin resistance in the brain [182]. GSK $3 \beta$ is thought to directly promote $A \beta$ production and stimulate the production of NFTs $[183,184]$. One of the downstream phosphorylation targets of GSK3 $\beta$ is tau, whose hyper-phosphorylation leads to its increased aggregation [106,185]. Indeed, tau protein phosphorylation was reported increased in the brain of T2D rats and effectively reduced after Exendin- 4 intervention. This was coupled with a rescued expression of PI3K and Akt and a decline in GSK3 $\beta$ activity indicating that GSK3 $\beta$ plays a role in tau phosphorylation in insulin-resistant brain [124]. Similarly in PD, GSK3 $\beta$ in post-mortem brains is enhanced and also colocalized with Lewy bodies indicating its possible pathological role [185]. In the 6-OHDA and MPTP models of PD, GSK3 $\beta$ is highly elevated and even actively disinhibited through protected phosphorylation events [186-188]. Interestingly, overexpression of $\alpha$-synuclein corresponds to an increase in GSK3 $\beta$ suggesting that $\alpha$-synuclein may cause enhanced GSK3 $\beta$ activity [189].

\section{Regulatory action of ferulic acid in PI3K/Akt signaling}

FA also imparts regulatory action on the PI3K/Akt and MAPK/ ERK signaling pathways $[93,190]$. The apoptotic activity of FA was completely inhibited in the presence of a PI3K inhibitor indicating that the anti-apoptotic effects of FA depend on the PI3K/Akt pathway. In addition, FA was shown to rescue the level of phosphorylated Akt and the downstream p70S6K in the glutamate toxicity model [92]. In terms of ERK, inhibition of ERK signaling in a model of glutamate toxicity partially abrogated the anti-apoptotic effect of FA [92]. Nevertheless, FA could prevent the decrease of ERK phosphorylation in the glutamate toxicity model, in a MAPK dependent manner [92]. Ultimately, through these pathways, FA effectively inhibits apoptosis activity by inhibiting caspase 3 activation and PARP cleavage.

In another model, middle cerebral artery occlusion (MCAO), rats who simultaneously received FA did not experience a decrease in the levels of phosphorylated Akt or elevated GSK3 $\beta$ and FA further attenuated the increase in phosphorylated CRMP-2 indicating that FA should indeed elicit an effect on Akt, ultimately affecting the GSK3 $\beta / C R M P$ signaling pathway [129]. In the same model, it was also shown that FA rescued the attenuated levels of mTOR, p70S6K and S6 phorphorylation levels describing its neuroprotective role [191]. Finally, another study confirmed that FA attenuated the ischemic injury-induced inactivation of PI3K and Akt signaling thereby promoting neuronal survival via its anti-apoptotic actions on Bad expression [191].

\section{Peroxisome proliferator-activated receptors}

PPARs are a family of three nuclear receptors PPAR $\alpha, \beta / \gamma$, that are highly expressed in metabolically active tissues. In response to a series of signaling ligands, their role is to regulate lipid metabolism, glucose homeostasis and enhance the action of insulin [192]. Due to their metabolic actions PPARs are intimately involved in the pathology of both diabetes and neurological disease.

One of the main ligands of PPARs are the essential fatty acids. Intriguingly, the gut microflora plays a prominent role in synthesizing and regulating fatty acids. In particular, the Bacteroidetes and Firmicutes phyla synthesize isomers of conjugated linoleic acid, a substrate of PPARs that erects anti-inflammatory action $[193,194]$. The probiotic Bifidobacterium breve is particularly efficient in this effect. Feeding $B$. breve to mice and pigs, there was not only significantly higher levels of EPA and DHA, but a reduction in inflammatory mediators, again possibly regulated through PPAR signaling [195].

Thiazolidinediones (TZDs), including rosiglitazone, are PPAR $\gamma$ agonists and many varieties are currently used as anti-diabetic drugs as they reduce insulin resistance and blood glucose levels in patients with T2D [196]. Interestingly, patients receiving such drugs were also protected from neurodegenerative pathologies. Indeed, PPAR $\gamma$ agonists promote neuronal development, protect cells from toxicity against various stresses and even protect neurons from $\mathrm{A} \beta$ toxicity and the accumulation of NFTs ultimately protecting the host from cognitive degeneration ( $\mathrm{rev}$ in [197]). The PPAR $\gamma$ agonist LSN862 were also shown to be protective against dopaminergic degeneration and inflammatory markers in the MPTP-model of PD [198]. Despite the abundance of clinical evidence, the precise mechanism PPAR $\gamma$ agonists' action remains to be fully elucidated. PPAR $\gamma$ agonists are potent anti-inflammatory and anti-oxidant agents thus contribute to the joint action on both diabetes and neurodegeneration. Also, PPAR $\gamma$ agonists intersect with the PI3K/Akt/TOR and MAPK/ERK signaling pathways to affect the underlying pathology of disease development (Figure 2). TZDs increase Akt phosphorylation and activation in a PI3K dependent manner [199]. TZDs also inhibit GSK3 $\beta$ thus providing neuroprotection by reducing the risk of apoptosis. In addition, TZDs increase the phosphorylation of ERK1/2 two-fold and the neuroprotective action was shown to be conducted in a MAPKdependent manner [200].

PPARs do induce the transcription of PTEN, an inhibitor of Akt activation. Albeit contradictory to the previous discussion on diabetic and neurodegenerative protective effects of Akt activation, this inhibitory effect in dependent on cell type [199] hence may not affect signaling in neither the pancreas nor in neurons. In fact, one PPAR $\gamma$ agonist even decreased the ischemia-reprofusion elevated of PTEN levels in neurons indicating a more complex regulatory scheme [201].

PPAR $\gamma$ activity is directly regulated by the gut microflora. Species in the Bacteroides genus targets RelA, an NFkB subunit for cytoplasmic redistribution. PPAR $\gamma$ is also relocated along with it as PPAR $\gamma$ is found in complex with nuclear RelA and goes forth to promote antiinflammatory actions [202]. Post-transcriptionally, Enterococcus faecalis regulates PPAR $\gamma$ activity through phosphorylation resulting in its enhanced, yet transient, transcriptional activation [203]. Indirectly, SCFAs such as butyrate produced from the gut microflora activate PPAR $\gamma$ enhancing its beneficial effects on glucose homeostasis and anti-inflammatory potential [204].

\section{Conclusion}

Chronic diseases including diabetes, $\mathrm{AD}$ and $\mathrm{PD}$ have an integrated and multifaceted etiology coupled with prominent imbalances in the gut microflora communities. Despite distinct disease characteristics, diabetes and neurodegenerative disorders are often found comorbid and even aggravate the other's severity linking each of these disorders to a common source. Hence, similarities in the kind of gut microflora 


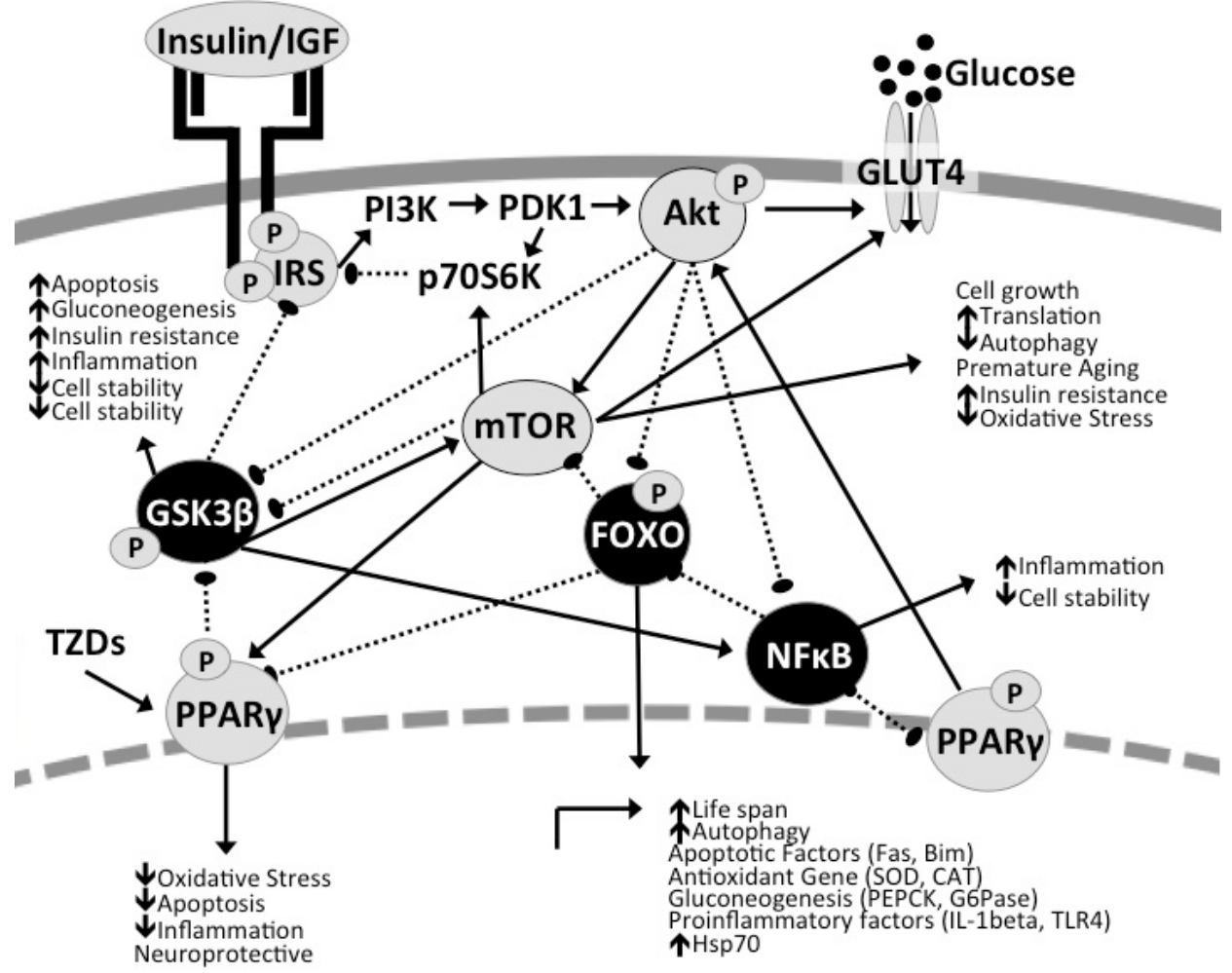

Figure 2: The interactions of intracellular signaling pathways implicated in diabetes and neurodegeneration. Insulin signaling initiates a series of protective intracellular signaling cascades that regulate systemic metabolic state, protect cells from apoptosis and reduce inflammation. In diabetes and neurodegenerative disease, reduced insulin signaling reduces activation of Akt and mTOR resulting in cell-destructive fate. Light grey shaded factors are generally regarded as neuroprotective or beneficial to maintaining cellular health and are upregulated in response to insulin signaling. Black-shaded factors are generally regarded as destructive and normally kept at low expression by normal insulin signaling. IGF = insulin-like growth factor; IRS = insulin receptor substrate; GLUT4 = glucose transporter 4 ; PI3K = phosphoinositide-3 kinase; PDK1 = phosphoinositidedependent kinase; $A k t=$ protein kinase B; p70S6K = ribosomal protein S6 kinase; Mtor = mammalian target of rapamycin; GSK3 $\beta=$ glucagon synthase kinase 3 beta; PPAR $\beta=$ peroxisome proliferator-activated receptor gamma; TZD = Thiozolidinedione; FOXO = Forkhead box 'O' type.

dysbiosis and correlated root causes like inflammation, metabolic stress and disrupted intracellular signaling indicate that maintaining a healthy gut environment is essential to prevent, treat and possibly reverse chronic disease. Probiotic and prebiotic treatment eradicate gastrointestinal dysbiosis and can ameliorate inflammatory, metabolic and molecular imbalances ultimately preventing or treating diabetes and neurodegenerative disease development. This opens the potential for new therapeutic approaches that incorporate gut microfloramodifying agents like probiotics to simultaneously treat several aspects of these complex disease pathologies. In particular, fermentation products including butyrate and ferulic acid have broad effects on inflammatory, oxidative and PI3K/Akt/mTOR signaling pathways therefore treatment with probiotics known to secrete these metabolites would benefit disease outcome.

Probiotics have vast potential for use in diabetes and other metabolic diseases as probiotics simultaneously target multiple aspects of the disease pathology. Through the mechanisms described above, probiotic therapies reduce insulin sensitivity, inflammation, oxidative stress and gastrointestinal distress thus ameliorating all major aspects of diabetic etiology. On the other hand, modern therapies including Metformin, Thiazolidinediones and GPL-1 agonists only affect insulin sensitivity or the secretion of insulin. The scope of these therapies is limited as they only influence the final manifestation of diabetes (insulin sensitivity) and do not address the underlying cause or the compounding action of inflammation, oxidative stress and gastrointestinal imbalances in diabetic patients. Hence, probiotics provide and novel and promising approach over conventional therapies to mitigate diverse aspects of diabetes possibly preventing or reversing the development of diabetes.

\section{Acknowledgments}

The authors would like to thank National Sciences and Engineering Research Committee (NSERC) for funding this research.

\section{References}

1. Ley RE, Turnbaugh PJ, Klein S, Gordon Jl (2006) Microbial ecology: human gut microbes associated with obesity. Nature 444: 1022-1023.

2. Gill SR, Pop M, Deboy RT, Eckburg PB, Turnbaugh PJ, et al. (2006) Metagenomic analysis of the human distal gut microbiome. Science 312: 13551359 .

3. Qin J, Li R, Raes J, Arumugam M, Burgdorf KS, et al. (2010) A human gut microbial gene catalogue established by metagenomic sequencing. Nature 464: 59-65.

4. Walsh CJ, Guinane CM, O'Toole PW, Cotter PD (2014) Beneficial modulation of the gut microbiota. FEBS Lett 588: 4120-4130.

5. Arumugam M, Raes J, Pelletier E, Le Paslier D, Yamada T, et al. (2011) Enterotypes of the human gut microbiome. Nature 473: 174-180.

6. Zipris D (2013) The interplay between the gut microbiota and the immune system in the mechanism of type 1 diabetes. Curr Opin Endocrinol Diabetes Obes 20: 265-270.

7. http://www.idf.org/worlddiabetesday/toolkit/gp/facts-figures

8. Cani PD, Osto M, Geurts L, Everard A (2012) Involvement of gut microbiota 
in the development of low-grade inflammation and type 2 diabetes associated with obesity. Gut Microbes 3: 279-288

9. Hoyer S (2003) Memory function and brain glucose metabolism. Pharmacopsychiatry 36: S62-67.

10. Piroli GG, Grillo CA, Charron MJ, McEwen BS, Reagan LP (2004) Biphasic effects of stress upon GLUT8 glucose transporter expression and trafficking in the diabetic rat hippocampus. Brain Res 1006: 28-35

11. Ramalingam M, Kim SJ (2014) Mechanisms of action of brain insulin against neurodegenerative diseases. J Neural Transm 121: 611-626.

12. Glass CK, Saijo K, Winner B, Marchetto MC, Gage FH (2010) Mechanisms underlying inflammation in neurodegeneration. Cell 140: 918-934.

13. Lees AJ, Hardy J, Revesz T (2009) Parkinson's disease. Lancet 373: 20552066.

14. Kravitz E, Schmeidler J, Schnaider Beeri M (2013) Type 2 diabetes and cognitive compromise: potential roles of diabetes-related therapies. Endocrinol Metab Clin North Am 42: 489-501.

15. Xu Q, Park Y, Huang X, Hollenbeck A, Blair A, et al. (2011) Diabetes and risk of Parkinson's disease. Diabetes Care 34: 910-915.

16. Steen E, Terry BM, Rivera EJ, Cannon JL, Neely TR, et al. (2005) Impaired insulin and insulin-like growth factor expression and signaling mechanisms in Alzheimer's disease--is this type 3 diabetes? J Alzheimers Dis 7: 63-80.

17. Knight AL, Yan X, Hamamichi S, Ajjuri RR, Mazzulli JR, et al. (2014) The glycolytic enzyme, GPI, is a functionally conserved modifier of dopaminergic neurodegeneration in Parkinson's models. Cell Metab 20: 145-157.

18. Sandyk R (1993) The relationship between diabetes mellitus and Parkinson's disease. Int J Neurosci 69: 125-130.

19. Papapetropoulos S, Ellul J, Argyriou AA, Talelli P, Chroni E, et al. (2004) The effect of vascular disease on late onset Parkinson's disease. Eur J Neurol 11: 231-235.

20. Pressley JC, Louis ED, Tang MX, Cote L, Cohen PD, et al. (2003) The impact of comorbid disease and injuries on resource use and expenditures in parkinsonism. Neurology 60: 87-93.

21. Morris JK, Esteves AR, Bomhoff GL, Swerdlow RH, Stanford JA, et al. (2010) Investigation of Insulin Signaling in Parkinson's Disease Cytoplasmic Hybrid Cells. FASEB J. 24 Meeting Abstract Supplement: 1053.6.

22. Giongo A, Gano KA, Crabb DB, Mukherjee N, Novelo LL, et al. (2011) Toward defining the autoimmune microbiome for type 1 diabetes. ISME J 5: 82-91.

23. Wu X, Ma C, Han L, Nawaz M, Gao F, et al. (2010) Molecular characterisation of the faecal microbiota in patients with type II diabetes. Curr Microbiol 61: 69-78

24. Karlsson FH, Tremaroli V, Nookaew I, Bergström G, Behre CJ, et al. (2013) Gu metagenome in European women with normal, impaired and diabetic glucose control. Nature 498: 99-103.

25. Qin J, Li Y, Cai Z, Li S, Zhu J, et al. (2012) A metagenome-wide association study of gut microbiota in type 2 diabetes. Nature 490: 55-60.

26. Vrieze A, Van Nood E, Holleman F, Salojärvi J, Kootte RS, et al. (2012) Transfer of intestinal microbiota from lean donors increases insulin sensitivity in individuals with metabolic syndrome. Gastroenterology 143: 913-916.

27. Roesch LF, Lorca GL, Casella G, Giongo A, Naranjo A, et al. (2009) Cultureindependent identification of gut bacteria correlated with the onset of diabetes in a rat model. ISME J 3: 536-548.

28. Brugman S, Klatter FA, Visser JTJ, Wildeboer-Veloo ACM, Harmsen HJM, et al. (2006) Antibiotic treatment partially protects against type 1 diabetes in the Bio-Breeding diabetes-prone rat. Is the gut flora involved in the development of type 1 diabetes? Diabetologia 49: 2105-2108.

29. Cheng J, Palva AM, de Vos WM, Satokari R (2013) Contribution of the intestina microbiota to human health: from birth to 100 years of age. Curr Top Microbio Immunol 358: 323-346.

30. Claesson MJ, Cusack S, O'Sullivan O, Greene-Diniz R, de Weerd $\mathrm{H}$, et al. (2011) Composition, variability, and temporal stability of the intestinal microbiota of the elderly. Proc Natl Acad Sci U S A 108 Suppl 1: 4586-4591.

31. Zheng LF, Wang ZY, Li XF, Song J, Hong F, et al. (2011) Reduced expression of choline acetyltransferase in vagal motoneurons and gastric motor dysfunction in a 6-OHDA rat model of Parkinson's disease. Brain Res 1420: 59-67.

32. Biagi E, Nylund L, Candela M, Ostan R, Bucci L, et al. (2010) Through ageing, and beyond: gut microbiota and inflammatory status in seniors and centenarians. PLoS One 5: e10667.

33. Scheperjans F, Aho V, Pereira PA, Koskinen K, Paulin L, et al. (2015) Gut microbiota are related to Parkinson's disease and clinical phenotype. Mov Disord 30: 350-358.

34. Pérez Martínez G, Bäuerl C, Collado MC (2014) Understanding gut microbiota in elderly's health will enable intervention through probiotics. Benef Microbes 5: 235-246.

35. Naseer MI, Bibi F, Alqahtani MH, Chaudhary AG, Azhar El, et al. (2014) Role of gut microbiota in obesity, type 2 diabetes and Alzheimer's disease. CNS Neurol Disord Drug Targets 13: 305-311.

36. Alam Q, ZubairAlam M, Karim S, Gan SH, Kamal MA, et al. (2014) A nanotechnological approach to the management of Alzheimer disease and type 2 diabetes. CNS Neurol Disord Drug Targets 13: 478-486.

37. Kunze WA, Mao YK, Wang B, Huizinga JD, Ma X, et al. (2009) Lactobacillus reuteri enhances excitability of colonic $\mathrm{AH}$ neurons by inhibiting calciumdependent potassium channel opening. J Cell Mol Med 13: 2261-2270.

38. Mao YK, Kasper DL, Wang B, Forsythe P, Bienenstock J, et al. (2013) Bacteroides fragilis polysaccharide $A$ is necessary and sufficient for acute activation of intestinal sensory neurons. Nat Commun 4: 1465.

39. Luyer MD, Greve JW, Hadfoune M, Jacobs JA, Dejong CH, et al. (2005) Nutritional stimulation of cholecystokinin receptors inhibits inflammation via the vagus nerve. J Exp Med 202: 1023-1029.

40. Cani PD, Hoste S, Guiot Y, Delzenne NM (2007) Dietary non-digestible carbohydrates promote L-cell differentiation in the proximal colon of rats. $\mathrm{Br}$ J Nutr 98: 32-37.

41. Tuohy KM, Rouzaud GC, Brück WM, Gibson GR (2005) Modulation of the human gut microflora towards improved health using prebiotics--assessment of efficacy. Curr Pharm Des 11: 75-90.

42. Valladares R, Sankar D, Li N, Williams E, Lai KK, et al. (2010) Lactobacillus johnsonii N6.2 mitigates the development of type 1 diabetes in BB-DP rats. PLoS One 5: e10507.

43. Yadav H, Jain S, Sinha PR (2007) Antidiabetic effect of probiotic dah containing Lactobacillus acidophilus and Lactobacillus casei in high fructose fed rats. Nutrition 23: 62-68.

44. Naito E, Yoshida Y, Makino K, Kounoshi Y, Kunihiro S, et al. (2011) Beneficial effect of oral administration of Lactobacillus casei strain Shirota on insulin resistance in diet-induced obesity mice. J Appl Microbiol 110: 650-657.

45. Franceschi C, Bonafè M, Valensin S, Olivieri F, De Luca M, et al. (2000) Inflamm-aging. An evolutionary perspective on immunosenescence. Ann N Y Acad Sci 908: 244-254.

46. Honda K, Littman DR (2012) The microbiome in infectious disease and inflammation. Annu Rev Immunol 30: 759-795.

47. De Felice FG, Lourenco MV, Ferreira ST (2014) How does brain insulin resistance develop in Alzheimer's disease? Alzheimers Dement 10: S26-32.

48. Franceschi C, Campisi J (2014) Chronic inflammation (inflammaging) and its potential contribution to age-associated diseases. J Gerontol A Biol Sci Med Sci 69 Suppl 1: S4-9.

49. Cani PD, Amar J, Iglesias MA, Poggi M, Knauf C, et al. (2007) Metabolic endotoxemia initiates obesity and insulin resistance. Diabetes 56: 1761-1772.

50. Cani PD, Possemiers S, Van de Wiele T, Guiot Y, Everard A, et al. (2009) Changes in gut microbiota control inflammation in obese mice through a mechanism involving GLP-2-driven improvement of gut permeability. Gut 58 : 1091-1103.

51. Cani PD, Bibiloni R, Knauf C, Waget A, Neyrinck AM, et al. (2008) Changes in gut microbiota control metabolic endotoxemia-induced inflammation in high-fat diet-induced obesity and diabetes in mice. Diabetes 57: 1470-1481.

52. Shi H, Kokoeva MV, Inouye K, Tzameli I, Yin H, et al. (2006) TLR4 links innate immunity and fatty acid-induced insulin resistance. J Clin Invest 116: 30153025 . 
53. Liu H-Q, Qiu Y, Mu Y, Zhang X-J, Liu L, et al. (2013) A high ratio of dietary $n-3 / n-6$ polyunsaturated fatty acids improves obesity-linked inflammation and insulin resistance through suppressing activation of TLR4 in SD rats. Nutr Res 33: 849-858.

54. Liang H, Hussey SE, Sanchez-Avila A, Tantiwong P, Musi N (2013) Effect of lipopolysaccharide on inflammation and insulin action in human muscle. PLoS ONE 8: e63983.

55. Rodes L, Khan A, Paul A, Coussa-Charley M, Marinescu D, et al. (2013) Effect of probiotics Lactobacillus and Bifidobacterium on gut-derived lipopolysaccharides and inflammatory cytokines: an in vitro study using a human colonic microbiota model. J Microbiol Biotechnol 23: 518-526.

56. Sood A, Midha V, Makharia GK, Ahuja V, Singal D, et al. (2009) The probiotic preparation, VSL\#3 induces remission in patients with mild-to-moderately active ulcerative colitis. Clin Gastroenterol Hepatol 7: 1202-1209, 1209.

57. Bibiloni R, Fedorak RN, Tannock GW, Madsen KL, Gionchetti P, et al. (2005) VSL\#3 probiotic-mixture induces remission in patients with active ulcerative colitis. Am J Gastroenterol 100: 1539-1546.

58. Wellen KE, Hotamisligil GS (2005) Inflammation, stress, and diabetes. J Clin Invest 115: 1111-1119.

59. Ding S, Chi MM, Scull BP, Rigby R, Schwerbrock NM, et al. (2010) High-fat diet: bacteria interactions promote intestinal inflammation which precedes and correlates with obesity and insulin resistance in mouse. PLoS One 5: e12191.

60. Anderson PD, Mehta NN, Wolfe ML, Hinkle CC, Pruscino L, et al. (2007) Innate immunity modulates adipokines in humans. J Clin Endocrinol Metab 92: 2272 2279.

61. Schulte BM, Lanke KH, Piganelli JD, Kers-Rebel ED, Bottino R, et al (2012) Cytokine and chemokine production by human pancreatic islets upon enterovirus infection. Diabetes 61: 2030-2036.

62. Wen L, Ley RE, Volchkov PY, Stranges PB, Avanesyan L, et al. (2008) Innate immunity and intestinal microbiota in the development of Type 1 diabetes. Nature 455: 1109-1113.

63. Hirsch EC, Hunot S (2009) Neuroinflammation in Parkinson's disease: a target for neuroprotection? Lancet Neurol 8: 382-397.

64. Hunter RL, Dragicevic N, Seifert K, Choi DY, Liu M, et al. (2007) Inflammation induces mitochondrial dysfunction and dopaminergic neurodegeneration in the nigrostriatal system. J Neurochem 100: 1375-1386.

65. McCoy MK, Tansey MG (2008) TNF signaling inhibition in the CNS: implications for normal brain function and neurodegenerative disease. J Neuroinflammation 5: 45

66. Ballatore C, Lee VM, Trojanowski JQ (2007) Tau-mediated neurodegeneration in Alzheimer's disease and related disorders. Nat Rev Neurosci 8: 663-672.

67. Pocivavsek A, Mikhailenko I, Strickland DK, Rebeck GW (2009) Microglia low-density lipoprotein receptor-related protein 1 modulates c-Jun $\mathrm{N}$-terminal kinase activation. J Neuroimmunol 214: 25-32.

68. Calcinaro F, Dionisi S, Marinaro M, Candeloro P, Bonato V, et al. (2005) Oral probiotic administration induces interleukin-10 production and prevents spontaneous autoimmune diabetes in the non-obese diabetic mouse. Diabetologia 48: 1565-1575.

69. Remely M, Aumueller E, Jahn D, Hippe B, Brath H, et al. (2014) Microbiota and epigenetic regulation of inflammatory mediators in type 2 diabetes and obesity. Benef Microbes 5: 33-43.

70. Hartstra AV, Bouter KE, Bäckhed F, Nieuwdorp M (2015) Insights into the role of the microbiome in obesity and type 2 diabetes. Diabetes Care 38: 159-165.

71. Schwiertz A, Taras D, Schäfer K, Beijer S, Bos NA, et al. (2010) Microbiota and SCFA in lean and overweight healthy subjects. Obesity (Silver Spring) 18 190-195.

72. Udayappan SD, Hartstra AV, Dallinga-Thie GM, Nieuwdorp M (2014) Intestina microbiota and faecal transplantation as treatment modality for insulin resistance and type 2 diabetes mellitus. Clin Exp Immunol 177: 24-29.

73. Di Sabatino A, Morera R, Ciccocioppo R, Cazzola P, Gotti S, et al. (2005) Ora butyrate for mildly to moderately active Crohn's disease. Aliment Pharmacol Ther 22: 789-794.

74. de Goffau MC, Luopajärvi K, Knip M, Ilonen J, Ruohtula T, et al. (2013) Fecal microbiota composition differs between children with $\beta$-cell autoimmunity and those without. Diabetes 62: 1238-1244.
75. Vernia P, Monteleone G, Grandinetti G, Villotti G, Di Giulio E, et al. (2000) Combined oral sodium butyrate and mesalazine treatment compared to ora mesalazine alone in ulcerative colitis: randomized, double-blind, placebocontrolled pilot study. Dig Dis Sci 45: 976-981.

76. Saha RN, Pahan K (2006) HATs and HDACs in neurodegeneration: a tale of disconcerted acetylation homeostasis. Cell Death Differ 13: 539-550.

77. Govindarajan N, Agis-Balboa RC, Walter J, Sananbenesi F, Fischer A (2011) Sodium butyrate improves memory function in an Alzheimer's disease mouse model when administered at an advanced stage of disease progression. J Alzheimers Dis 26: 187-197.

78. Rane P, Shields J, Heffernan M, Guo Y, Akbarian S, et al. (2012) The histone deacetylase inhibitor, sodium butyrate, alleviates cognitive deficits in pre-motor stage PD. Neuropharmacology 62: 2409-2412.

79. St Laurent R, O'Brien LM, Ahmad ST (2013) Sodium butyrate improves locomotor impairment and early mortality in a rotenone-induced Drosophila model of Parkinson's disease. Neuroscience 246: 382-390.

80. Mancuso C, Santangelo R2 (2014) Ferulic acid: pharmacological and toxicological aspects. Food Chem Toxicol 65: 185-195

81. Tomaro-Duchesneau C, Saha S, Malhotra M, Coussa-Charley M, Al-Salam $\mathrm{H}$, et al. (2012) Lactobacillus fermenum NCIMB 5221 has a greater ferulic acid production compared to other ferulic acid esterase producing Lactobacilli. International Journal of Probiotics and Prebiotics 7: 23-32.

82. Roy S, Metya SK, Sannigrahi S, Rahaman N, Ahmed F (2013) Treatment with ferulic acid to rats with streptozotocin-induced diabetes: effects on oxidative stress, pro-inflammatory cytokines, and apoptosis in the pancreatic $\beta$ cell. Endocrine 44: 369-379.

83. Prabhakar PK, Prasad R, Ali S, Doble M (2013) Synergistic interaction of ferulic acid with commercial hypoglycemic drugs in streptozotocin induced diabetic rats. Phytomedicine 20: 488-494.

84. Jung EH, Kim SR, Hwang IK, Ha TY (2007) Hypoglycemic effects of a phenolic acid fraction of rice bran and ferulic acid in C57BL/KsJ-db/db mice. J Agric Food Chem 55: 9800-9804

85. Gogoi B, Chatterjee P, Mukherjee S, Buragohain AK, Bhattacharya S, et al. (2014) A polyphenol rescues lipid induced insulin resistance in skeletal muscle cells and adipocytes. Biochem Biophys Res Commun 452: 382-388.

86. Tomaro-Duchesneau C, Saha S, Malhotra M, Jones ML, Labbé A, et al (2014) Effect of orally administered L. fermentum NCIMB 5221 on markers of metabolic syndrome: an in vivo analysis using ZDF rats. Appl Microbiol Biotechnol 98: 115-126.

87. Xu X, Xiao H, Zhao J, Zhao T (2012) Cardioprotective effect of sodium ferulate in diabetic rats. Int J Med Sci 9: 291-300.

88. Chen J, Lin D, Zhang C, Li G, Zhang N, et al. (2015) Antidepressant-like effects of ferulic acid: involvement of serotonergic and norepinergic systems. Metab Brain Dis 30: 129-136.

89. K M DJ, Muralidhara (2014) Neuroprotective efficacy of a combination of fish oil and ferulic acid against 3-nitropropionic acid-induced oxidative stress and neurotoxicity in rats: behavioural and biochemical evidence. Appl Physiol Nutr Metab 39: 487-496.

90. Kanski J, Aksenova M, Stoyanova A, Butterfield DA (2002) Ferulic acid antioxidant protection against hydroxyl and peroxyl radical oxidation in synaptosomal and neuronal cell culture systems in vitro: structure-activity studies. J Nutr Biochem 13: 273-281.

91. Trombino S, Cassano R, Ferrarelli T, Barone E, Picci N, et al. (2013) Transferulic acid-based solid lipid nanoparticles and their antioxidant effect in rat brain microsomes. Colloids Surf B Biointerfaces 109: 273-279.

92. Jin Y, Yan EZ, Fan Y, Guo XL, Zhao YJ, et al. (2007) Neuroprotection by sodium ferulate against glutamate-induced apoptosis is mediated by ERK and PI3 kinase pathways. Acta Pharmacol Sin 28: 1881-1890.

93. Jin Y, Yan EZ, Li XM, Fan Y, Zhao YJ, et al. (2008) Neuroprotective effect of sodium ferulate and signal transduction mechanisms in the aged rat hippocampus. Acta Pharmacol Sin 29: 1399-1408.

94. Yan JJ, Cho JY, Kim HS, Kim KL, Jung JS, et al. (2001) Protection agains beta-amyloid peptide toxicity in vivo with long-term administration of ferulic acid. Br J Pharmacol 133: 89-96.

95. Pi R, Mao X, Chao X, Cheng Z, Liu M, et al. (2012) Tacrine-6-ferulic acid, a 
novel multifunctional dimer, inhibits amyloid- $\beta$-mediated Alzheimer's diseaseassociated pathogenesis in vitro and in vivo. PLoS One 7: e31921.

96. Mori T, Koyama N, Guillot-Sestier MV, Tan J, Town T (2013) Ferulic acid is a nutraceutical $\beta$-secretase modulator that improves behavioral impairment and alzheimer-like pathology in transgenic mice. PLoS One 8: e55774.

97. Yan JJ, Jung JS, Kim TK, Hasan A, Hong CW, et al. (2013) Protective effects of ferulic acid in amyloid precursor protein plus presenilin-1 transgenic mouse model of Alzheimer disease. Biol Pharm Bull 36: 140-143.

98. Tsai FS, Wu LY, Yang SE, Cheng HY, Tsai CC, et al. (2015) Ferulic acid reverses the cognitive dysfunction caused by amyloid $\beta$ peptide 1-40 through anti-oxidant activity and cholinergic activation in rats. Am J Chin Med 43: 319335.

99. Kim MJ, Choi SJ, Lim ST, Kim HK, Heo HJ, et al. (2007) Ferulic acid supplementation prevents trimethyltin-induced cognitive deficits in mice. Biosci Biotechnol Biochem 71: 1063-1068.

100. Krause M, Heck TG, Bittencourt A, Scomazzon SP, Newsholme P, et al. (2015) The chaperone balance hypothesis: the importance of the extracellular to intracellular HSP70 ratio to inflammation-driven type 2 diabetes, the effect of exercise, and the implications for clinical management. Mediators Inflamm 2015: 249205 .

101. Sultana R, Ravagna A, Mohmmad-Abdul H, Calabrese V, Butterfield DA (2005) Ferulic acid ethyl ester protects neurons against amyloid beta- peptide(1-42)induced oxidative stress and neurotoxicity: relationship to antioxidant activity. J Neurochem 92: 749-758.

102. Bassil F, Fernagut PO, Bezard E, Meissner WG (2014) Insulin, IGF-1 and GLP1 signaling in neurodegenerative disorders: targets for disease modification? Prog Neurobiol 118: 1-18.

103. Hölscher C (2014) Central effects of GLP-1: new opportunities for treatments of neurodegenerative diseases. J Endocrinol 221: T31-41.

104. Bitel CL, Kasinathan C, Kaswala RH, Klein WL, Frederikse PH (2012) Amyloid- $\beta$ and tau pathology of Alzheimer's disease induced by diabetes in a rabbit animal model. J Alzheimers Dis 32: 291-305.

105. Umegaki H (2014) Impaired glycemia and Alzheimer's disease. Neurobio Aging 35: e21.

106. Moloney AM, Griffin RJ, Timmons S, O'Connor R, Ravid R, et al. (2010) Defects in IGF-1 receptor, insulin receptor and IRS-1/2 in Alzheimer's disease indicate possible resistance to IGF-1 and insulin signalling. Neurobiol Aging 31: 224-243.

107. Talbot K, Wang HY, Kazi H, Han LY, Bakshi KP, et al. (2012) Demonstrated brain insulin resistance in Alzheimer's disease patients is associated with IGF1 resistance, IRS-1 dysregulation, and cognitive decline. J Clin Invest 122 1316-1338.

108. O' Neill C (2013) PI3-kinase/Akt/mTOR signaling: impaired on/off switches in aging, cognitive decline and Alzheimer's disease. Exp Gerontol 48: 647-653.

109.De Felice FG, Vieira MN, Bomfim TR, Decker H, Velasco PT, et al. (2009) Protection of synapses against Alzheimer's-linked toxins: insulin signaling prevents the pathogenic binding of Abeta oligomers. Proc Natl Acad Sci U S A 106: 1971-1976.

110. Zhao WQ, De Felice FG, Fernandez S, Chen H, Lambert MP, et al. (2008) Amyloid beta oligomers induce impairment of neuronal insulin receptors. FASEB J 22: 246-260

111. Gao S, Duan C, Gao G, Wang X, Yang H (2015) Alpha-synuclein overexpression negatively regulates insulin receptor substrate 1 by activating mTORC1/S6K1 signaling. Int J Biochem Cell Biol 64: 25-33.

112. Morris JK, Zhang H, Gupte AA, Bomhoff GL, Stanford JA, et al. (2008) Measures of striatal insulin resistance in a 6-hydroxydopamine model of Parkinson's disease. Brain Res 1240: 185-195.

113. Contreras-Zárate MJ, Niño A, Rojas L, Arboleda H, Arboleda G (2015) Silencing of PINK1 inhibits insulin-like growth factor-1-mediated receptor activation and neuronal survival. J Mol Neurosci 56: 188-197.

114. Cani PD, Lecourt E, Dewulf EM, Sohet FM, Pachikian BD, et al. (2009) Gut microbiota fermentation of prebiotics increases satietogenic and incretin gut peptide production with consequences for appetite sensation and glucose response after a meal. Am J Clin Nutr 90: 1236-1243.
115. Garber AJ (2011) Long-acting glucagon-like peptide 1 receptor agonists: review of their efficacy and tolerability. Diabetes Care 34 Suppl 2: S279-284.

116. Accardi G, Caruso C, Colonna-Romano G, Camarda C, Monastero R, et al (2012) Can Alzheimer disease be a form of type 3 diabetes? Rejuvenation Res 15: 217-221.

117. Bomfim TR, Forny-Germano L, Sathler LB, Brito-Moreira J, Houzel JC, et al. (2012) An anti-diabetes agent protects the mouse brain from defective insulin signaling caused by Alzheimer's disease- associated $A \hat{l}^{2}$ oligomers. J Clin Invest 122: 1339-1353.

118. Bak AM, Egefjord L, Gejl M, Steffensen C, Stecher CW, et al. (2011) Targeting amyloid-beta by glucagon-like peptide -1 (GLP-1) in Alzheimer's disease and diabetes. Expert Opin Ther Targets 15: 1153-1162.

119. Hölscher C (2014) Drugs developed for treatment of diabetes show protective effects in Alzheimer's and Parkinson's diseases. Sheng Li Xue Bao 66: 497510.

120. Grillo CA, Piroli GG, Hendry RM, Reagan LP (2009) Insulin-stimulated translocation of GLUT4 to the plasma membrane in rat hippocampus is PI3 kinase dependent. Brain Res 1296: 35-45.

121. Mehla J, Chauhan BC, Chauhan NB (2014) Experimental induction of type 2 diabetes in aging-accelerated mice triggered Alzheimer-like pathology and memory deficits. J Alzheimers Dis 39: 145-162.

122. Yang HT, Sheen YJ, Kao CD, Chang CA, Hu YC, et al. (2013) Association between the characteristics of metabolic syndrome and Alzheimer's disease. Metab Brain Dis 28: 597-604.

123. Hansen HH, Fabricius K, Barkholt P, Niehoff ML, Morley JE, et al. (2015) The GLP-1 Receptor Agonist Liraglutide Improves Memory Function and Increases Hippocampal CA1 Neuronal Numbers in a Senescence-Accelerated Mouse Model of Alzheimer's Disease. J Alzheimers Dis.

124. Xu W, Yang Y, Yuan G, Zhu W, Ma D, et al. (2015) Exendin-4, a glucagonlike peptide-1 receptor agonist, reduces Alzheimer disease-associated tau hyperphosphorylation in the hippocampus of rats with type 2 diabetes. $J$ Investig Med 63: 267-272.

125. Harkavyi A, Abuirmeileh A, Lever R, Kingsbury AE, Biggs CS, et al. (2008) Glucagon-like peptide 1 receptor stimulation reverses key deficits in distinct rodent models of Parkinson's disease. J Neuroinflammation 5: 19.

126. Li Y, Perry T, Kindy MS, Harvey BK, Tweedie D, et al. (2009) GLP-1 recepto stimulation preserves primary cortical and dopaminergic neurons in cellular and rodent models of stroke and Parkinsonism. Proc Natl Acad Sci U S A 106: $1285-1290$.

127. Brachmann SM, Ueki K, Engelman JA, Kahn RC, Cantley LC (2005) Phosphoinositide 3-kinase catalytic subunit deletion and regulatory subunit deletion have opposite effects on insulin sensitivity in mice. Mol Cell Biol 25 1596-1607.

128. Guo S1 (2014) Insulin signaling, resistance, and the metabolic syndrome: insights from mouse models into disease mechanisms. J Endocrinol 220: T1 $1 \mathrm{~T} 23$.

129. Gim SA, Sung JH, Shah FA, Kim MO, Koh PO (2013) Ferulic acid regulates the AKT/GSK-3ß/CRMP-2 signaling pathway in a middle cerebral artery occlusion animal model. Lab Anim Res 29: 63-69.

130. Wang Y, Inoue H, Ravnskjaer K, Viste K, Miller N, et al. (2010) Targeted disruption of the CREB coactivator Crtc2 increases insulin sensitivity. Proc Natl Acad Sci U S A 107: 3087-3092.

131. Cohen P, Frame S (2001) The renaissance of GSK3. Nat Rev Mol Cell Biol 2: 769-776

132. Shibata M, Yamawaki T, Sasaki T, Hattori H, Hamada J, et al. (2002) Upregulation of Akt phosphorylation at the early stage of middle cerebral artery occlusion in mice. Brain Res 942: 1-10.

133. Malagelada C, Jin ZH, Greene LA (2008) RTP801 is induced in Parkinson's disease and mediates neuron death by inhibiting Akt phosphorylation/ activation. J Neurosci 28: 14363-14371.

134. Gutiérrez-Venegas G, Cardoso-Jiménez $P$ (2011) Lipoteichoic acid promotes nuclear accumulation of $\beta$-catenin via AKT in human gingival fibroblasts. Int Immunopharmacol 11: 1278-1284.

135. Cortés-Vieyra R, Bravo-Patiño A, Valdez-Alarcón JJ, Juárez MC, Finlay BB 
et al. (2012) Role of glycogen synthase kinase-3 beta in the inflammatory response caused by bacterial pathogens. J Inflamm (Lond) 9: 23.

136. Cani PD, Knauf C, Iglesias MA, Drucker DJ, Delzenne NM, et al. (2006) Improvement of glucose tolerance and hepatic insulin sensitivity by oligofructose requires a functional glucagon-like peptide 1 receptor. Diabetes 55: $1484-1490$

137. Yan F, Cao H, Cover TL, Whitehead R, Washington MK, et al. (2007) Soluble proteins produced by probiotic bacteria regulate intestinal epithelial cell survival and growth. Gastroenterology 132: 562-575.

138. Hoarau C, Martin L, Faugaret D, Baron C, Dauba A, et al. (2008) Supernatant from bifidobacterium differentially modulates transduction signaling pathways for biological functions of human dendritic cells. PLOS ONE 3: e2753.

139. Khamzina L, Veilleux A, Bergeron S, Marette A (2005) Increased activation of the mammalian target of rapamycin pathway in liver and skeletal muscle of obese rats: possible involvement in obesity-linked insulin resistance. Endocrinology 146: 1473-1481.

140. Gupta A, Dey CS (2012) PTEN, a widely known negative regulator of insulin/ $\mathrm{PI} 3 \mathrm{~K}$ signaling, positively regulates neuronal insulin resistance. Mol Biol Cell 23: $3882-3898$

141.Bae EJ, Xu J, Oh DY, Bandyopadhyay G, Lagakos WS, et al. (2012) Liverspecific p70 S6 kinase depletion protects against hepatic steatosis and systemic insulin resistance. J Biol Chem 287: 18769-18780.

142. Buller CL, Loberg RD, Fan MH, Zhu Q, Park JL, et al. (2008) A GSK-3/TSC2/ mTOR pathway regulates glucose uptake and GLUT1 glucose transporter expression. Am J Physiol Cell Physiol 295: C836-843.

143. Miao XY, Gu ZY, Liu P, Hu Y, Li L, et al. (2013) The human glucagon-like peptide-1 analogue liraglutide regulates pancreatic beta-cell proliferation and apoptosis via an AMPK/mTOR/P70S6K signaling pathway. Peptides 39: 71 79.

144. Chang GR, Wu YY, Chiu YS, Chen WY, Liao JW, et al. (2009) Long-term administration of rapamycin reduces adiposity, but impairs glucose tolerance in high-fat diet-fed KK/HIJ mice. Basic Clin Pharmacol Toxicol 105: 188-198.

145. Schindler CE, Partap U, Patchen BK, Swoap SJ (2014) Chronic rapamycin treatment causes diabetes in male mice. Am J Physiol Regul Integr Comp Physiol 307: R434-443.

146. Um SH, Frigerio F, Watanabe M, Picard F, Joaquin M, et al. (2004) Absence of S6K1 protects against age- and diet-induced obesity while enhancing insulin sensitivity. Nature 431: 200-205.

147. Briaud I, Dickson LM, Lingohr MK, McCuaig JF, Lawrence JC, et al. (2005) Insulin receptor substrate-2 proteasomal degradation mediated by a mammalian target of rapamycin (mTOR)-induced negative feedback downregulates protein kinase B-mediated signaling pathway in beta-cells. J Biol Chem 280: 2282-2293.

148. Blagosklonny MV (2011) Rapamycin-induced glucose intolerance: hunger or starvation diabetes. Cell Cycle 10: 4217-4224.

149. Ueno M, Carvalheira JB, Tambascia RC, Bezerra RM, Amaral ME, et al. (2005) Regulation of insulin signalling by hyperinsulinaemia: role of IRS-1/2 serine phosphorylation and the mTOR/p70 S6K pathway. Diabetologia 48: 506-518.

150. Perluigi M, Di Domenico F, Butterfield DA (2015) mTOR signaling in aging and neurodegeneration: At the crossroad between metabolism dysfunction and impairment of autophagy. Neurobiol Dis.

151. Caccamo A, Majumder S, Richardson A, Strong R, Oddo S (2010) Molecular interplay between mammalian target of rapamycin (mTOR), amyloid-beta, and Tau: effects on cognitive impairments. J Biol Chem 285: 13107-13120.

152. Tramutola A, Triplett JC, Di Domenico F, Niedowicz DM, Murphy MP, et al. (2015) Alteration of mTOR signaling occurs early in the progression of Alzheimer disease (AD): analysis of brain from subjects with pre-clinical $A D$, amnestic mild cognitive impairment and late-stage AD. J Neurochem 133: 739-749.

153. Sun YX, Ji X, Mao X, Xie L, Jia J, et al. (2014) Differential activation of mTOR complex 1 signaling in human brain with mild to severe Alzheimer's disease. $J$ Alzheimers Dis 38: 437-444.

154. Ma YQ, Wu DK, Liu JK (2013) mTOR and tau phosphorylated proteins in the hippocampal tissue of rats with type 2 diabetes and Alzheimer's disease. Mol Med Rep 7: 623-627.
155. Rieker C, Engblom D, Kreiner G, Domanskyi A, Schober A, et al. (2011) Nucleolar disruption in dopaminergic neurons leads to oxidative damage and parkinsonism through repression of mammalian target of rapamycin signaling J Neurosci 31: 453-460.

156. Xu Y, Liu C, Chen S, Ye Y, Guo M, et al. (2014) Activation of AMPK and inactivation of Akt result in suppression of mTOR-mediated S6K1 and 4EBP1 pathways leading to neuronal cell death in in vitro models of Parkinson's disease. Cell Signal 26: 1680-1689.

157. Storelli G, Defaye A, Erkosar B, Hols P, Royet J, et al. (2011) Lactobacillus plantarum promotes Drosophila systemic growth by modulating hormonal signals through TOR-dependent nutrient sensing. Cell Metab 14: 403-414.

158. Wang Y, Zhou Y, Graves DT (2014) FOXO transcription factors: their clinical significance and regulation. Biomed Res Int 2014: 925350.

159.Schmoll D, Walker KS, Alessi DR, Grempler R, Burchell A, et al. (2000) Regulation of glucose-6-phosphatase gene expression by protein kinase Balpha and the forkhead transcription factor FKHR. Evidence for insulin response unit-dependent and -independent effects of insulin on promoter activity. J Biol Chem 275: 36324-36333.

160. Xiong X, Tao R, DePinho RA, Dong XC (2013) Deletion of hepatic FoxO1/3/4 genes in mice significantly impacts on glucose metabolism through downregulation of gluconeogenesis and upregulation of glycolysis. PLoS One 8: e74340.

161.Zhang W, Patil S, Chauhan B, Guo S, Powell DR, et al. (2006) FoxO1 regulates multiple metabolic pathways in the liver: effects on gluconeogenic, glycolytic, and lipogenic gene expression. J Biol Chem 281: 10105-10117.

162. Nakae J, Biggs WH 3rd, Kitamura T, Cavenee WK, Wright CV, et al. (2002) Regulation of insulin action and pancreatic beta-cell function by mutated alleles of the gene encoding forkhead transcription factor Foxo1. Nat Genet 32: $245-253$.

163. Fan W, Imamura T, Sonoda N, Sears DD, Patsouris D, et al. (2009) FOXO1 transrepresses peroxisome proliferator-activated receptor gamma transactivation, coordinating an insulin-induced feed-forward response in adipocytes. J Biol Chem 284: 12188-12197.

164. van der Vos KE, Eliasson $P$, Proikas-Cezanne T, Vervoort SJ, van Boxtel $R$, et al. (2012) Modulation of glutamine metabolism by the PI(3)K-PKB-FOXO network regulates autophagy. Nat Cell Biol 14: 829-837.

165. Chen CC, Jeon SM, Bhaskar PT, Nogueira V, Sundararajan D, et al. (2010) FoxOs inhibit mTORC1 and activate Akt by inducing the expression of Sestrin3 and Rictor. Dev Cell 18: 592-604.

166. Ambrogini E, Almeida M, Martin-Millan M, Paik JH, Depinho RA, et al. (2010) FoxO-mediated defense against oxidative stress in osteoblasts is indispensable for skeletal homeostasis in mice. Cell Metab 11: 136-146.

167. Buteau J, Accili D (2007) Regulation of pancreatic beta-cell function by the forkhead protein FoxO1. Diabetes Obes Metab 9 Suppl 2: 140-146.

168. Chiribau CB, Cheng L, Cucoranu IC, Yu YS, Clempus RE, et al. (2008) FOXO3A regulates peroxiredoxin III expression in human cardiac fibroblasts. Jiol Chem 283: 8211-8217.

169.Ponugoti B, Dong G, Graves DT (2012) Role of forkhead transcription factors in diabetes-induced oxidative stress. Exp Diabetes Res 2012: 939751.

170.Perez FP, Bose D, Maloney B, Nho K, Shah K, et al. (2014) Late-onset Alzheimer's disease, heating up and foxed by several proteins: pathomolecular effects of the aging process. J Alzheimers Dis 40: 1-17.

171. Wang Y, Zhou Y, Graves DT (2014) FOXO transcription factors: their clinical significance and regulation. Biomed Res Int 2014: 925350

172. Su D, Coudriet GM, Hyun Kim D, Lu Y, Perdomo G, et al. (2009) FoxO1 links insulin resistance to proinflammatory cytokine IL-1beta production in macrophages. Diabetes 58: 2624-2633.

173. Dumitriu A, Latourelle JC, Hadzi TC, Pankratz N, Garza D, et al. (2012) Gene expression profiles in Parkinson disease prefrontal cortex implicate FOXO1 and genes under its transcriptional regulation. PLoS Genet 8: e1002794.

174. Pino E, Amamoto R, Zheng L, Cacquevel M, Sarria JC, et al. (2014) FOXO3 determines the accumulation of $\alpha$-synuclein and controls the fate of dopaminergic neurons in the substantia nigra. Hum Mol Genet 23: 1435-1452.

175. Clancy DJ, Gems D, Harshman LG, Oldham S, Stocker H, et al. (2001) 
Extension of life-span by loss of $\mathrm{CHICO}$, a Drosophila insulin receptor substrate protein. Science 292: 104-106.

176. Koh H, Kim H, Kim MJ, Park J, Lee HJ, et al. (2012) Silent information regulator 2 (Sir2) and Forkhead box O (FOXO) complement mitochondrial dysfunction and dopaminergic neuron loss in Drosophila PTEN-induced kinase 1 (PINK1) null mutant. J Biol Chem 287: 12750-12758.

177. Leng S, Zhang W, Zheng Y, Liberman Z, Rhodes CJ, et al. (2010) Glycogen synthase kinase 3 beta mediates high glucose-induced ubiquitination and proteasome degradation of insulin receptor substrate 1. J Endocrinol 206: 171-181.

178. Cline GW, Johnson K, Regittnig W, Perret P, Tozzo E, et al. (2002) Effects of a novel glycogen synthase kinase-3 inhibitor on insulin-stimulated glucose metabolism in Zucker diabetic fatty (fa/fa) rats. Diabetes 51: 2903-2910.

179. Wagman AS, Johnson KW, Bussiere DE (2004) Discovery and development of GSK3 inhibitors for the treatment of type 2 diabetes. Curr Pharm Des 10 $1105-1137$

180. Inoki K, Li Y, Zhu T, Wu J, Guan KL (2002) TSC2 is phosphorylated and inhibited by Akt and suppresses mTOR signalling. Nat Cell Biol 4: 648-657.

181. Golpich M, Amini E, Hemmati F, Ibrahim NM, Rahmani B, et al. (2015) Glycogen synthase kinase-3 beta (GSK-3 $\beta$ ) signaling: Implications for Parkinson's disease. Pharmacol Res 97: 16-26.

182. Leroy K, Yilmaz Z, Brion JP (2007) Increased level of active GSK-3beta in Alzheimer's disease and accumulation in argyrophilic grains and in neurones at different stages of neurofibrillary degeneration. Neuropathol Appl Neurobio 33: $43-55$

183. Asuni AA, Hooper C, Reynolds CH, Lovestone S, Anderton BH, et al. (2006) GSK3alpha exhibits beta-catenin and tau directed kinase activities that are modulated by Wnt. Eur J Neurosci 24: 3387-3392.

184. Liu Y, Liu F, Grundke-lqbal I, lqbal K, Gong CX (2011) Deficient brain insulin signalling pathway in Alzheimer's disease and diabetes. J Pathol 225: 54-62.

185. Nagao M, Hayashi $H$ (2009) Glycogen synthase kinase-3beta is associated with Parkinson's disease. Neurosci Lett 449: 103-107.

186. Chen G, Bower KA, Ma C, Fang S, Thiele CJ, et al. (2004) Glycogen synthase kinase 3beta (GSK3beta) mediates 6-hydroxydopamine-induced neuronal death. FASEB J 18: 1162-1164.

187. Hernandez-Baltazar D, Mendoza-Garrido ME, Martinez-Fong D (2013) Activation of GSK-3 $\beta$ and caspase-3 occurs in Nigral dopamine neurons during the development of apoptosis activated by a striatal injection of 6-hydroxydopamine. PLoS One 8: e70951.

188. Petit-Paitel A, Brau F, Cazareth J, Chabry J (2009) Involvment of cytosolic and mitochondrial GSK-3beta in mitochondrial dysfunction and neuronal cell death of MPTP/MPP-treated neurons. PLoS One 4: e5491.

189. Duka T, Duka V, Joyce JN, Sidhu A (2009) Alpha-Synuclein contributes to GSK-3beta-catalyzed Tau phosphorylation in Parkinson's disease models. FASEB J 23: 2820-2830.

190. Jin MH, Lee YH, Kim JM, Sun HN, Moon EY, et al. (2005) Characterization of neural cell types expressing peroxiredoxins in mouse brain. Neurosci Lett 381: $252-257$

191.Koh PO (2013) Ferulic acid attenuates focal cerebral ischemia-induced decreases in p70S6 kinase and S6 phosphorylation. Neurosci Lett 555: 7-11.

192. Gelman L, Feige JN, Desvergne B (2007) Molecular basis of selective PPARgamma modulation for the treatment of Type 2 diabetes. Biochim Biophys Acta 1771: 1094-1107

193. Devillard E, Mclntosh FM, Duncan SH, Wallace RJ (2007) Metabolism of linoleic acid by human gut bacteria: different routes for biosynthesis of conjugated linoleic acid. J Bacteriol 189: 2566-2570.

194. Gorissen L, Raes K, Weckx S, Dannenberger D, Leroy F, et al. (2010) Production of conjugated linoleic acid and conjugated linolenic acid isomers by Bifidobacterium species. Appl Microbiol Biotechnol 87: 2257-2266.

195. Wall R, Ross RP, Shanahan F, O'Mahony L, O'Mahony C, et al. (2009) Metabolic activity of the enteric microbiota influences the fatty acid composition of murine and porcine liver and adipose tissues. Am J Clin Nutr 89: 1393-1401.

196. Ryan KK, Li B, Grayson BE, Matter EK, Woods SC, et al. (2011) A role for central nervous system PPAR- $\beta$ in the regulation of energy balance. Nat Med 17: 623-626.
197. Quintanilla RA, Utreras E, Cabezas-Opazo FA (2014) Role of PPAR $\beta$ in the Differentiation and Function of Neurons. PPAR Res 2014: 768594.

198. Swanson CR, Du E, Johnson DA, Johnson JA, Emborg ME (2013) Neuroprotective Properties of a Novel Non-Thiazoledinedione Partial PPAR$\hat{i}^{3}$ Agonist against MPTP. PPAR Res 2013: 582809.

199. Kim KY, Cho HS, Jung WH, Kim SS, Cheon HG (2007) Phosphatase and tensin homolog deleted on chromosome 10 suppression is an important process in peroxisome proliferator-activated receptor-gamma signaling in adipocytes and myotubes. Mol Pharmacol 71: 1554-1562.

200. Rosa AO, Egea J, Martínez A, García AG, López MG (2008) Neuroprotective effect of the new thiadiazolidinone NP00111 against oxygen-glucose deprivation in rat hippocampal slices: implication of ERK1/2 and PPARgamma receptors. Exp Neurol 212: 93-99.

201. Kim KY, Cho HS, Lee SH, Ahn JH, Cheon HG (2011) Neuroprotective effects of KR-62980, a new PPAR $\hat{I}^{3}$ agonist, against chemical ischemia-reperfusion in SK-N-SH cells. Brain Res 1372: 103-114.

202. Kelly D, Campbell JI, King TP, Grant G, Jansson EA, et al. (2004) Commensa anaerobic gut bacteria attenuate inflammation by regulating nuclearcytoplasmic shuttling of PPAR-gamma and RelA. Nat Immunol 5: 104-112.

203. Are A1, Aronsson L, Wang S, Greicius G, Lee YK, et al. (2008) Enterococcus faecalis from newborn babies regulate endogenous PPARgamma activity and IL-10 levels in colonic epithelial cells. Proc Natl Acad Sci U S A 105: 19431948.

204. Jones JR, Barrick C, Kim KA, Lindner J, Blondeau B, et al. (2005) Deletion of PPARgamma in adipose tissues of mice protects against high fat diet-induced obesity and insulin resistance. Proc Natl Acad Sci U S A 102: 6207-6212.

205. Mitsuma T, Odajima H, Momiyama Z, Watanabe K, Masuguchi M, et al. (2008) Enhancement of gene expression by a peptide $\mathrm{p}$ (CHWPR) produced by Bifidobacterium lactis BB-12. Microbiol Immunol 52: 144-155.

206. LE TK, Hosaka T, LE TT, Nguyen TG, Tran QB, et al. (2014) Oral administration of Bifidobacterium spp. improves insulin resistance, induces adiponectin, and prevents inflammatory adipokine expressions. Biomed Res 35: 303-310.

207.Szwajgier D, Dmowska K (2010) Novel Ferulic Acid Esterasesfrom Bifidobacterium Sp. Produced on Selected Synthetic and Natural Carbon Sources. Acta Sci Pol Technol Aliment 9: 305-318.

208. Bomhof MR, Saha DC, Reid DT, Paul HA, Reimer RA (2014) Combined effects of oligofructose and Bifidobacterium animalis on gut microbiota and glycemia in obese rats. Obesity (Silver Spring) 22: 763-771.

209. Guyonnet D, Chassany O, Bucrotte P, Picard C, Mouret M, et al. (2007) Effect of a fermented milk containing Bifidobacterium animalis DN-173 010 on the health-related quality of life and symptoms in irritable bowel syndrome in adults in primary care: a multicentre, randomized, double-blind, controlled trial. Aliment Pharmacol Ther 26: 475-486.

210. Whorwell PJ, Altringer L, Morel J, Bond Y, Charbonneau D, et al. (2006) Efficacy of an encapsulated probiotic Bifidobacterium infantis 35624 in women with irritable bowel syndrome. Am J Gastroenterol 101: 1581-1590.

211. Sato N, Morishita R (2014) Brain alterations and clinical symptoms of dementia in diabetes: aß/tau-dependent and independent mechanisms. Front Endocrinol (Lausanne) 5: 143.

212. Murri M, Leiva I, Gomez-Zumaquero JM, Tinahones FJ, Cardona F, et al (2013) Gut microbiota in children with type 1 diabetes differs from that in healthy children: a case-control study. BMC Med 11: 46.

213. Bravo JA, Julio-Pieper M, Forsythe P, Kunze W, Dinan TG, et al. (2012) Communication between gastrointestinal bacteria and the nervous system. Curr Opin Pharmacol 12: 667-672.

214. Bhathena J, Duchesneau CT (2012) Effect of Orally Administered Microencapsulated FA-Producing L. fermentum on Markers of Metabolic Syndrome: An In Vivo Analysis. J Diabetes Metab 01

215. Hsieh FC1, Lee CL, Chai CY, Chen WT, Lu YC, et al. (2013) Oral administration of Lactobacillus reuteri GMNL-263 improves insulin resistance and ameliorates hepatic steatosis in high fructose-fed rats. Nutr Metab (Lond) 10: 35

216. Yadav H, Jain S, Sinha PR (2008) Oral administration of dahi containing probiotic Lactobacillus acidophilus and Lactobacillus casei delayed the progression of streptozotocin-induced diabetes in rats. J Dairy Res 75: 189195. 
Citation: Westfall S, Lomis N, Singh SP, Dai SY, Prakash S (2015) The Gut Microflora and its Metabolites Regulate the Molecular Crosstalk between Diabetes and Neurodegeneration. J Diabetes Metab 6: 577. doi:10.4172/2155-6156.1000577

217. Ushakova G, Fed'kiv O, Prykhod'ko O, Pierzynowski S, Kruszewska D (2009) The effect of long-term lactobacilli (lactic acid bacteria) enteral treatment on the central nervous system of growing rats. J Nutr Biochem 20: 677-684.

218. Pereira DIA, McCartney AL, Gibson GR (2003) An in vitro study of the probiotic potential of a bile-salt-hydrolyzing Lactobacillus fermentum strain, and determination of its cholesterol-lowering properties. Applied and Environmental Microbiology 69: 4743-4752.

219. Zhang Y, Wang L, Zhang J, Li Y, He Q, et al. (2014) Probiotic Lactobacillus casei Zhang ameliorates high-fructose-induced impaired glucose tolerance in hyperinsulinemia rats. Eur J Nutr 53: 221-232.

220.Bejar W, Hamden K, Ben Salah R, Chouayekh H (2013) Lactobacillus plantarum TN627 significantly reduces complications of alloxan-induced diabetes in rats. Anaerobe 24: 4-11.

221. Park JE, Oh SH, Cha YS (2014) Lactobacillus plantarum LG42 isolated from gajami sik-hae decreases body and fat pad weights in diet-induced obese mice. J Appl Microbiol 116: 145-156.

222. Sakai T, Taki T, Nakamoto A, Shuto E, Tsutsumi R, et al. (2013) Lactobacillus plantarum OLL2712 regulates glucose metabolism in C57BL/6 mice fed a high-fat diet. J Nutr Sci Vitaminol (Tokyo) 59: 144-147.

223. Kim SW, Park KY, Kim B, Kim E, Hyun CK (2013) Lactobacillus rhamnosus GG improves insulin sensitivity and reduces adiposity in high-fat diet-fed mice through enhancement of adiponectin production. Biochem Biophys Res Commun 431: 258-263.

224. Kato M, Asaka M, Shimizu Y, Nobuta A, Takeda H, et al. (2004) Relationship between Helicobacter pylori infection and the prevalence, site and histological type of gastric cancer. Aliment Pharmacol Ther 20 Suppl 1: 85-89.

225. Fetissov SO, Hamze Sinno M, Coëffier M, Bole-Feysot C, Ducrotté $P$, et al. (2008) Autoantibodies against appetite-regulating peptide hormones and neuropeptides: putative modulation by gut microflora. Nutrition 24: 348-359.

226. Round JL, Mazmanian SK (2010) Inducible Foxp3+ regulatory T-cell development by a commensal bacterium of the intestinal microbiota. Proc Natl Acad Sci U S A 107: 12204-12209.

227. Tsuda Y, Yoshimatsu Y, Aoki H, Nakamura K, Irie M, et al. (2007) Clinical effectiveness of probiotics therapy (BIO-THREE) in patients with ulcerative colitis refractory to conventional therapy. Scandinavian Journal of Gastroenterology 42: 1306-1311.

228. Larsen N, Vogensen FK, van den Berg FW, Nielsen DS, Andreasen AS, et al (2010) Gut microbiota in human adults with type 2 diabetes differs from nondiabetic adults. PLoS One 5: e9085.

229. Sato J, Kanazawa A, Ikeda F, Yoshihara T, Goto H, et al. (2014) Gut dysbiosis and detection of "live gut bacteria" in blood of Japanese patients with type 2 diabetes. Diabetes Care 37: 2343-2350.

230. Clayton EM, Rea MC, Shanahan F, Quigley EM, Kiely B, et al. (2009) The vexed relationship between Clostridium difficile and inflammatory bowe disease: an assessment of carriage in an outpatient setting among patients in remission. Am J Gastroenterol 104: 1162-1169.

231. Sokol H, Pigneur B, Watterlot L, Lakhdari O, Bermúdez-Humarán LG, et al. (2008) Faecalibacterium prausnitzii is an anti-inflammatory commensal bacterium identified by gut microbiota analysis of Crohn disease patients. Proc Natl Acad Sci U S A 105: 16731-16736.

232. Pekkala S, Munukka E, Kong L, Pöllänen E, Autio R, et al. (2015) Tolllike receptor 5 in obesity: the role of gut microbiota and adipose tissue inflammation. Obesity (Silver Spring) 23: 581-590.

233. Sysi-Aho M, Ermolov A, Gopalacharyulu PV, Tripathi A, Seppänen-Laakso $\mathrm{T}$, et al. (2011) Metabolic regulation in progression to autoimmune diabetes. PLoS Comput Biol 7: e1002257.

234.Sasaki M, Ogasawara N, Funaki Y, Mizuno M, lida A, et al. (2013) Transglucosidase improves the gut microbiota profile of type 2 diabetes mellitus patients: a randomized double-blind, placebo-controlled study. BMC Gastroenterol 13: 81.

235. Krych L, Nielsen DS, Hansen AK, Hansen CH (2015) Gut microbial markers are associated with diabetes onset, regulatory imbalance, and IFN- $\beta$ level in NOD mice. Gut Microbes 6: 101-109.

236. Brown CT, Davis-Richardson AG, Giongo A, Gano KA, Crabb DB, et al. (2011) Gut microbiome metagenomics analysis suggests a functional model for the development of autoimmunity for type 1 diabetes. PLoS One 6: e25792.

237. Chen Z, Guo L, Zhang Y, Walzem RL, Pendergast JS, et al. (2014) Incorporation of therapeutically modified bacteria into gut microbiota inhibits obesity. J Clin Invest 124: 3391-3406. 